\title{
Separating Dynamic and Thermodynamic Impacts of Climate Change on Daytime Convective Development over Land
}

\author{
Wojciech W. Grabowski AND ANDREAS F. Prein \\ Mesoscale and Microscale Meteorology Laboratory, National Center for Atmospheric Research, Boulder, Colorado
}

(Manuscript received 3 January 2019, in final form 12 April 2019)

\begin{abstract}
Climate change affects the dynamics and thermodynamics of moist convection. Changes in the dynamics concern, for instance, an increase of convection strength due to increases of convective available potential energy (CAPE). Thermodynamics involve increases in water vapor that the warmer atmosphere can hold and convection can work with. Small-scale simulations are conducted to separate these two components for daytime development of unorganized convection over land. The simulations apply a novel modeling technique referred to as the piggybacking approach and consider the global climate model (GCM)-predicted change of atmospheric temperature and moisture profiles in the Amazon region at the end of the century under a business-as-usual scenario. The simulations show that the dynamic impact dominates because changes in cloudiness and rainfall come from cloud dynamics considerations, such as the change in CAPE and convective inhibition (CIN) combined with the impact of environmental relative humidity $(\mathrm{RH})$ on deep convection. The small $\mathrm{RH}$ reduction between the current and future climate significantly affects the mean surface rain accumulation as it changes from a small reduction to a small increase when the RH decrease is eliminated. The thermodynamic impact on cloudiness and precipitation is generally small, with the extreme rainfall intensifying much less than expected from an atmospheric moisture increase. These results are discussed in the context of previous studies concerning climate change-induced modifications of moist convection. Future research directions applying the piggybacking method are discussed.
\end{abstract}

\section{Introduction}

Climate change is argued to intensify the hydrologic cycle (Huntington 2006; Held and Soden 2006; Giorgi et al. 2011), resulting in an intensification and higher frequencies of extreme precipitation events (Alexander et al. 2006; Min et al. 2011; Prein et al. 2017b). Global mean precipitation is expected to increase by $2 \% \mathrm{~K}^{-1}$ warming due to energetic constraints (Allen and Ingram 2002; Trenberth et al. 2003). In contrast, extreme precipitation can increase at higher rates (Trenberth et al. 2003; Westra et al. 2014) but the underlying processes that control this intensification are not fully understood (Westra et al. 2014). Estimates range from $6.5 \% \mathrm{~K}^{-1}$ warming (Trenberth et al. 2003; Westra et al. 2013; Prein et al. 2017b), which is close to the increase in the saturation mixing ratio according to the Clausius-Clapeyron relationship, to much larger than $6.5 \% \mathrm{~K}^{-1}$ warming called super Clausius-Clapeyron scaling (Lenderink and van Meijgaard 2008; Guerreiro et al. 2018; Haerter and Berg 2009; Kendon et al. 2014). The large differences in

\footnotetext{
Corresponding author: Wojciech W. Grabowski, grabow@ ucar.edu
}

these estimations originate from differences in location, processes involved, and the methodology used to estimate scaling rates (e.g., Schär et al. 2016; X. Zhang et al. 2017)

One of the main challenges in estimating climate change impacts on extreme precipitation are short, sparse, and inhomogeneous observational records and major biases and uncertainties in the simulation of extreme precipitation in state-of-the-art climate models (Trenberth et al. 2017). This is mainly due to the coarse grid spacing of these models that require uncertain subgrid-scale parameterizations (most importantly cumulus parameterization to simulate convective precipitation) and model inability to resolve important land surface characteristics such as orography. The former is a major source of model errors and uncertainty in climate simulations (Molinari and Dudek 1992; Jones and Randall 2011; Sherwood et al. 2014; Mooney et al. 2017).

Convection-permitting models that use horizontal grid spacings of $1-4 \mathrm{~km}$ do not need deep convection

Publisher's Note: This article was revised on 18 January 2021 at the request of the authors to remove some outmoded language. 
parameterizations and therefore significantly improve the simulation of extreme convective precipitation (Prein et al. 2013; Ban et al. 2014; Chan et al. 2014). Studies using this kind of models show a consistent intensification of extreme precipitation, especially on subdaily time scales in the future (Kendon et al. 2014; Ban et al. 2015; Prein et al. 2017b). Related to this is an increase of convective available potential energy (CAPE; Muller et al. 2011; Muller and O'Gorman 2011; Romps 2016; Prein et al. 2017a; Hoogewind et al. 2017) resulting in an increase of updraft velocities especially in the middle and upper troposphere. At the same time, convection-permitting models also predict a decrease of light to moderate precipitation frequencies (Ban et al. 2015; Prein et al. 2017b; Rasmussen et al. 2017). Using a convection-permitting model Rasmussen et al. (2017) associate this with an increase in convective inhibition (CIN). They hypothesize that an increasing CIN suppresses weak convective storms and results in the accumulation of larger CAPE resulting in fewer storms but more intense precipitation. Similarly, Thackeray et al. (2018) show that global climate models that have a strong increase in future heavy precipitation also show a strong decrease in moderate and weak precipitation.

A general problem with convection-permitting models is the treatment of turbulent processes and shallow convection [see Prein et al. (2015) for a review]. Turbulent mixing in the boundary layer and the representation of shallow convection are essential to capture the surface energy budget and to destabilize the atmosphere in weakly forced environments (e.g., Wu et al. 2009). Because of still relatively coarse spatial resolution, convection-permitting models underestimate entrainment into convective updrafts resulting in too strong and too deep convection (Bryan and Morrison 2012; Lebo and Morrison 2015).

Tropical precipitation rates are strongly linked to the available water vapor in the whole atmospheric column (e.g., Bretherton et al. 2004; Muller et al. 2009; Neelin et al. 2009). However, changes in the tropical precipitation and particular its extremes are thought to depend more on the water vapor in the lower atmosphere than the integral over the whole column (Muller et al. 2011). Climate models predict small changes in relative humidity due to global warming that range from $-5 \%$ over land to $+2 \%$ over oceans, suggesting that atmospheric water vapor increases close to the Clausius-Clapeyron relation (O'Gorman and Muller 2010; Laîné et al. 2014). The increase in integrated water vapor with climate change is often argued to result in stronger updrafts but the troposphere may also become more stable due to warming, counteracting updraft intensifications due to increased latent heating (Del Genio et al. 2007).
To improve our understanding of these complex interactions involving tropical convection and precipitation we apply high-resolution simulations that are able to capture turbulent processes across a wide range of scales. In addition, we use a novel modeling methodology that allows separation of impacts due to convective dynamics (e.g., higher CAPE and thus stronger updrafts) from effects of thermodynamics (e.g., increased water vapor in a warmer climate) on simulated clouds and precipitation. This pilot study compares daytime convective development in the Amazon region using idealized environments from the late twentieth century and a projected environment at the end of the twentyfirst century. Daytime convective development is the key process over summertime continents, with initially dry near-surface convection developing within a cloudfree morning atmosphere and leading to the formation of a well-mixed boundary layer. As the boundary layer deepens, shallow convective clouds develop near the boundary layer top, and they eventually transition to precipitating deep convection in midday. Only uppertropospheric anvils, remnants of deep convection, are left when the surface forcing diminishes in the afternoon and evening hours. The anvils can persist for several hours, slowly dissipating after sunset. This textbook evolution can be simulated applying an idealized modeling setup of Grabowski et al. (2006).

The next section provides details of the model and modeling case. Results are discussed in section 3. Additional higher-resolution shorter simulations targeting the shallow convection phase are presented in section 4 . Section 5 provides a brief discussion and conclusions of the study.

\section{The model, methodology, and modeling case}

The cloud model and modeling setup are the same as in Grabowski (2015), Grabowski and Morrison (2016, 2017), and Grabowski (2018). The model is a simplified serial version of the 3D nonhydrostatic anelastic Eulerian-semi-Lagrangian (EULAG) model (http://www. mmm.ucar.edu/eulag/). The setup represents daytime convective development over warm-season continents due to evolving surface latent and sensible heat fluxes. The horizontally uniform surface fluxes are prescribed as in Grabowski et al. (2006, see the appendix therein). They increase from zero at the simulation onset, reach maximum of 554 and $270 \mathrm{~W} \mathrm{~m}^{-2}$ for latent and sensible fluxes, respectively, at hour 5.25 (i.e., 1245 local time), decrease to zero at hour 10.5 (i.e., 1800 local time), and are zero for the final hour and a half of the simulation. The impact of interactive surface fluxes using the same modeling case and horizontally uniform 
surface conditions (i.e., allowing horizontal variations of surface fluxes with the domain-averaged fluxes close to the prescribed evolution) was recently investigated in Kurowski et al. (2018). Eventually, one should also consider the application of a land surface model to mimic a more complete land-atmosphere coupling. However, only a simple approach following Grabowski et al. (2006) is applied in this pilot study. Evolving radiative tendencies prescribed in Grabowski et al. (2006) are not used as in previous studies of Grabowski (2015) and Grabowski and Morrison 2016, 2017). We apply a horizontally periodic horizontal domain of $50 \mathrm{~km} \times$ $50 \mathrm{~km}$. Although relatively small, the domain is similar to that used in simulations discussed in Grabowski et al. (2006) and it allows development a few deep convective clouds at hour 6 . The horizontal domain is covered with a uniform 400-m grid. In the vertical, the domain extends up to $24 \mathrm{~km}$, applying 81 levels with a stretched grid. The vertical grid length is around $100 \mathrm{~m}$ near the surface, with about a dozen levels below $1.5 \mathrm{~km}$. The grid length increases to around 300 and $400 \mathrm{~m}$ at 5 and $15 \mathrm{~km}$, respectively. The model time step is $3 \mathrm{~s}$.

The simulations apply the double-moment warmrain and ice microphysics schemes of Morrison and Grabowski $(2007,2008 \mathrm{a}, \mathrm{b})$ that explicitly predict the in-cloud supersaturation and include cloud condensation nuclei $(\mathrm{CCN})$ activation. The latter links the concentration of cloud droplets to the assumed CCN characteristics. For the simulations discussed in this paper, the pristine double-mode $\mathrm{CCN}$ spectrum is assumed as in section 4 in Grabowski and Morrison (2016) and in Grabowski (2018). The first mode is described by total $\mathrm{CCN}$ number mixing ratio of $100 \mathrm{mg}^{-1}$, and the mean dry radius, geometric standard deviation of the distribution, and the soluble fraction are assumed as $0.05 \mu \mathrm{m}, 2.0$, and 0.7 , respectively. For the second mode, the total CCN number mixing ratio is taken as $500 \mathrm{mg}^{-1}$ and the mean dry radius of $0.01 \mu \mathrm{m}$; other parameters for the second mode are the same as for the first mode. $\mathrm{CCN}$ processing by clouds is not considered, and $\mathrm{CCN}$ characteristics remain unchanged as the simulations progress.

We apply the piggybacking methodology used in shallow convection simulations of Grabowski (2014) and Grabowski and Jarecka (2015) and in deep convection simulations of Grabowski (2015, 2018), and Grabowski and Morrison (2016, 2017). The piggybacking is to apply two sets of thermodynamic variables in a single cloud field simulation, the first one coupled to the dynamics and driving the simulated flow (set D, for driver) and the second one piggybacking the simulated flow (set $\mathrm{P}$, for piggybacker). This is explained in more detail in the appendix. Piggybacking allows for detecting
TABLE 1. CMIP5 global climate models used for deriving average climate change perturbations in the $\mathrm{CLCH}$ simulations.

\begin{tabular}{lc}
\hline \hline CMIP5 model & Realization \\
\hline ACCESS1.3 & r1i1p1 \\
CanESM2 & r1i1p1 \\
CCSM4 & r1i1p1 \\
CESM1-CAM5 & r1i1p1 \\
CMCC-CM & r1i1p1 \\
CNRM-CM5 & r2i1p1 \\
CSIRO-Mk3.6.0 & r1i1p1 \\
GFDL CM3 & r1i1p1 \\
GFDL-ESM2M & r1i1p1 \\
GISS-E2-H & r1i1p1 \\
HadGEM2-CC & r1i1p1 \\
HadGEM2-ES & r2i1p1 \\
INM-CM4 & r1i1p1 \\
IPSL-CM5A-MR & r1i1p1 \\
MIROC5 & r1i1p1 \\
MIROC-ESM & r1i1p1 \\
MPI-ESM-LR & r1i1p1 \\
MPI-ESM-MR & r1i1p1 \\
MRI-CGCM3 & r1i1p1
\end{tabular}

small impacts on bulk cloud properties, such as the cloud cover, liquid and ice water path, and surface precipitation. It also allows for comparing local cloud buoyancies between the $\mathrm{D}$ and $\mathrm{P}$ sets and thus exploring impacts on the cloud dynamics. We keep the microphysics the same in all simulations presented here (the pristine double-mode $\mathrm{CCN}$ case as explained above) and change the initial sounding in which convection develops (i.e., current vs future climate) similarly to Grabowski (2018). The key aspect is that driverpiggybacker differences come from thermodynamic considerations, whereas the difference between drivers reflects the impact of climate change on convective dynamics.

We use the pseudo-global warming methodology (Schär et al. 1996; Kawase et al. 2009; Rasmussen et al. 2011) to investigate the effect of climate change on the Amazon environment. The standard sounding from the 1999 field project (Grabowski et al. 2006) is used to represent current climate conditions. We perturb the temperature and relative humidity of this sounding by the average February mean climate change signal derived from 19 general circulation models from phase 5 of the Coupled Model Intercomparison Project (CMIP5) (see Table 1) using the closest grid cell to the sounding location $\left(11^{\circ} \mathrm{S}, 62.6^{\circ} \mathrm{W}\right)$. Climate change signals correspond to the difference of future 2070-99 minus 1970-99 current climate conditions assuming a businessas-usual RCP8.5 radiative forcing (van Vuuren et al. 2011). The CMIP5 projections do not agree on the sign of mean precipitation changes at this location but show consistent decreases in low-level $\mathrm{RH}$ and decreasing 

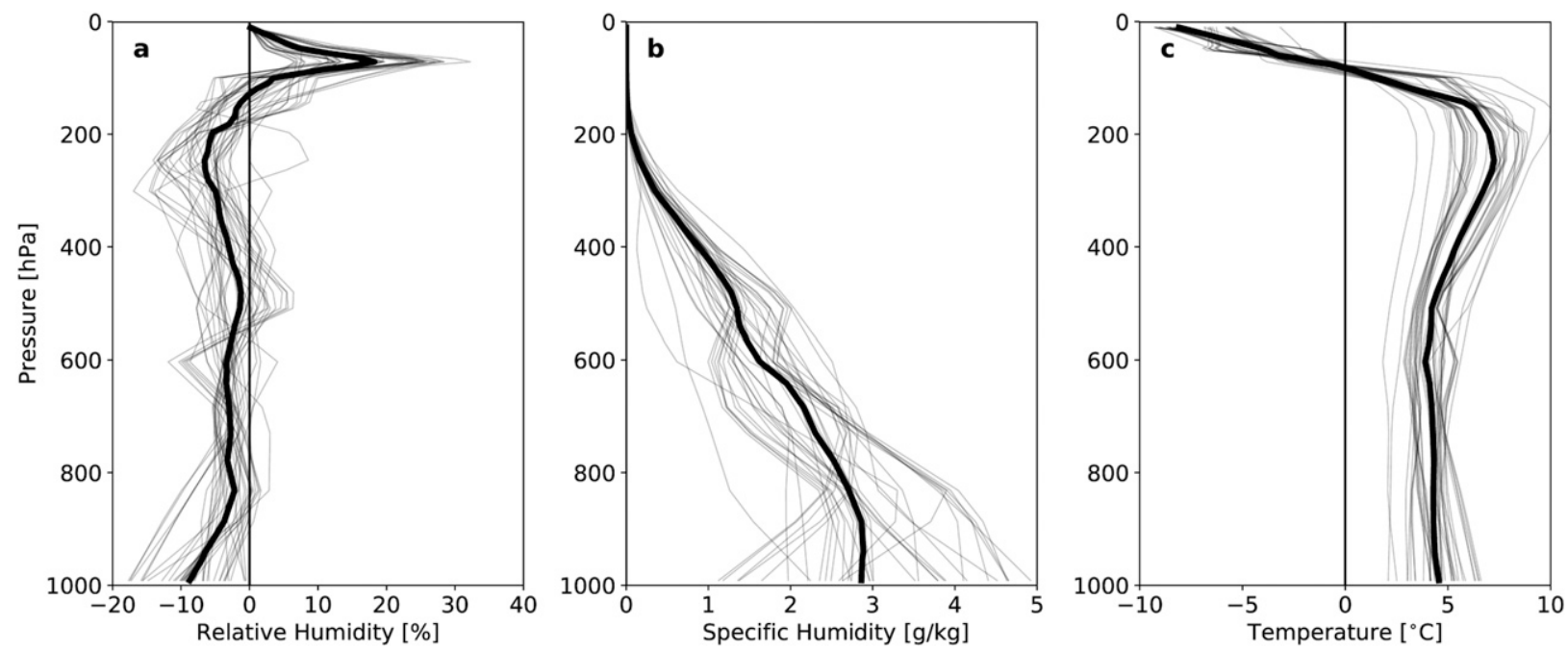

FIG. 1. Profiles of the change in (a) relative humidity, (b) specific humidity, and (c) temperature between CMIP5 global climate models. Thin lines show the changes in individual simulations, and the thick line shows the average change.

tropospheric lapse rates, which is similar to many other tropical land areas (IPCC 2013). Increases in extreme precipitation in the Amazon basin are more robust among CMIP5 models and similar to other tropical regions (Bador et al. 2018). This indicates that climate change signals at our study location should be representative of tropical land areas but further analysis is necessary to determine if this is the case.

The climate change signals that are added to the current climate sounding are shown in Fig. 1. The initial sounding from Grabowski et al. (2006) is referred to as CNTR (i.e., "Control"). The climate change sounding described above is referred to as CLCH (i.e., "climate change"). It features warmer troposphere (by about $4 \mathrm{~K}$ below $5 \mathrm{~km}$ and close to $8 \mathrm{~K}$ around $10 \mathrm{~km}$; Fig. $1 \mathrm{c}$ ), increase of the specific humidity (Fig. 1b), and reduced tropospheric relative humidity (RH; Fig. 1a). The latter is because specific humidity increases are smaller than expected by Clausius-Clapeyron scaling. Because the relative humidity change differs more between climate models than the temperature change (cf. Fig. 1), we also consider an initial sounding that features the same temperature change as $\mathrm{CLCH}$, but keeps $\mathrm{RH}$ the same as in the CNTR sounding, that is, following exactly the Clausius-Clapeyron scaling. This sounding is referred to as CCRH (i.e., "climate change with the same RH"). The precipitable water is about 57,73 , and $76 \mathrm{~kg} \mathrm{~m}^{-2}$ for CNTR, CLCH, and CCRH, respectively.

Figure 2 shows results of the pseudoadiabatic parcel analysis for CNTR, CLCH, and CCRH soundings. The initial parcel conditions come from averaging temperature and moisture over the lowest $500 \mathrm{~m}$. CAPE (the vertical integral of the positive pseudoadiabatic parcel buoyancy) increases from about $1200 \mathrm{~J} \mathrm{~kg}^{-1}$ for CNTR to about $2200 \mathrm{~J} \mathrm{~kg}^{-1}$ for CLCH and to about $3800 \mathrm{~J} \mathrm{~kg}^{-1}$ for $\mathrm{CCRH}$. The differences between the three soundings build up over most of the troposphere, with the level of neutral buoyancy increasing from about $14 \mathrm{~km}$ for CNTR to about $16 \mathrm{~km}$ for CLCH and even slightly higher for CCRH. There are also differences in CIN, the absolute value of the lower-tropospheric negative pseudoadiabatic parcel buoyancy integral (not shown in Fig. 1, but to be discussed in the next section). CIN is about $18 \mathrm{~J} \mathrm{~kg}^{-1}$ for CNTR, about $11 \mathrm{~J} \mathrm{~kg}^{-1}$ for CCRH, and about $43 \mathrm{~J} \mathrm{~kg}^{-1}$ for CLCH, again highlighting the role of the lower tropospheric moisture. Many previous studies suggest that CAPE increases due to climate change (e.g., Muller et al. 2011; Romps 2016; Prein et al. 2017a) while increases in CIN were documented fairly recently (e.g., Rasmussen et al. 2017).

Two sets of piggybacking simulations are conducted applying the three soundings. The first set features CNTR and CLCH conditions, with each one driving and then piggybacking, that is, D-CNTR/P-CLCH in the first simulation and D-CLCH/P-CNTR in the second simulation ("D" and "P" stand for driving and piggybacking as explained above). The second set features CNTR and CCRH conditions with D-CNTR/P-CCRH in the first simulation and D-CCRH/P-CNTR in the second simulation. Finally, we use three-member mini-ensembles to improve the robustness of the results by including different realizations of each simulation. Different ensemble members are generated by applying different sequences of random numbers that are used in temperature and moisture perturbations at the start and are periodically added during the simulation [see Grabowski 


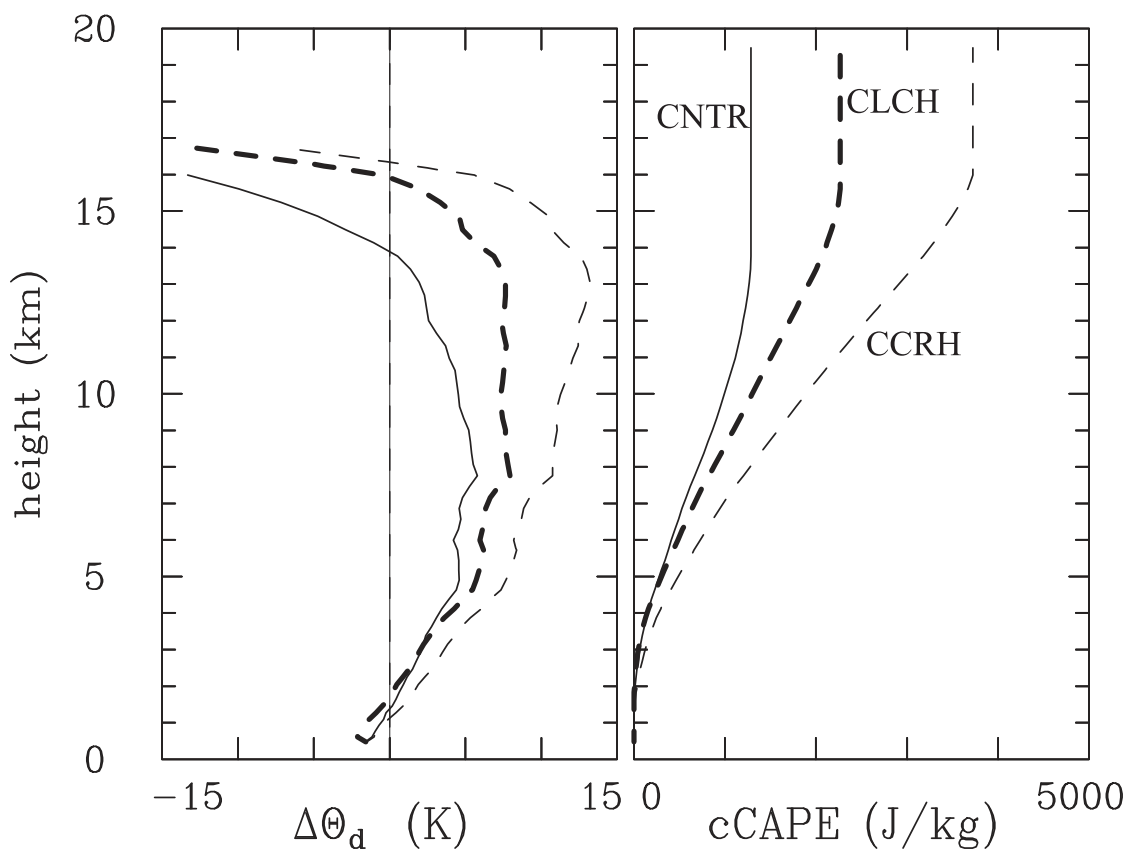

FIG. 2. Pseudoadiabatic parcel analysis of the CNTR, CLCH, and CCRH initial profiles, showing (left) the density potential temperature increase over the environment and (right) the cumulative convective available potential energy (cCAPE). Solid thin and dashed thick/thin lines are for CNTR and CLCH/CCRH soundings, respectively.

et al. (2006) for details]. Simulation results are saved as snapshots of model fields every 6 min of the simulation time. Surface precipitation is saved every $3 \mathrm{~min}$ as the average over all time steps from the preceding 3-min period. These two datasets are used in the analysis discussed below.

\section{Results}

\section{a. Evolutions of CAPE and CIN}

Figure 3 shows evolutions of CAPE and CIN from initial values throughout the 12 -h simulations. Horizontally averaged temperature and moisture profiles from drivers in all CNTR, CLCH, and CCRH sets are used to calculate CAPE and CIN, with the initial pseudoadiabatic parcel conditions taken as averages of the temperature and moisture profiles over $500 \mathrm{~m}$ near the surface (i.e., as in Fig. 2). CAPE increases and CIN decreases during the initial few hours because of the boundary layer heating and moistening by the surface heat fluxes. This agrees with previous studies (e.g., Guichard et al. 2004; see Fig. 4 therein). CAPE reaches a maximum at about the time $\mathrm{CIN}$ reaches values close to zero. This happens about $2 \mathrm{~h}$ later in the CLCH ensemble mostly because the initial CIN is much higher in $\mathrm{CLCH}$ than in CNTR. As will be shown later in the paper, reducing CIN to zero does not automatically translate into shallow-to-deep convection transition as this happens between hours 4 and 5 for CNTR and $\mathrm{CCRH}$, and even later for CLCH. As argued in Grabowski et al. (2006), gradual deepening of the cloud field despite
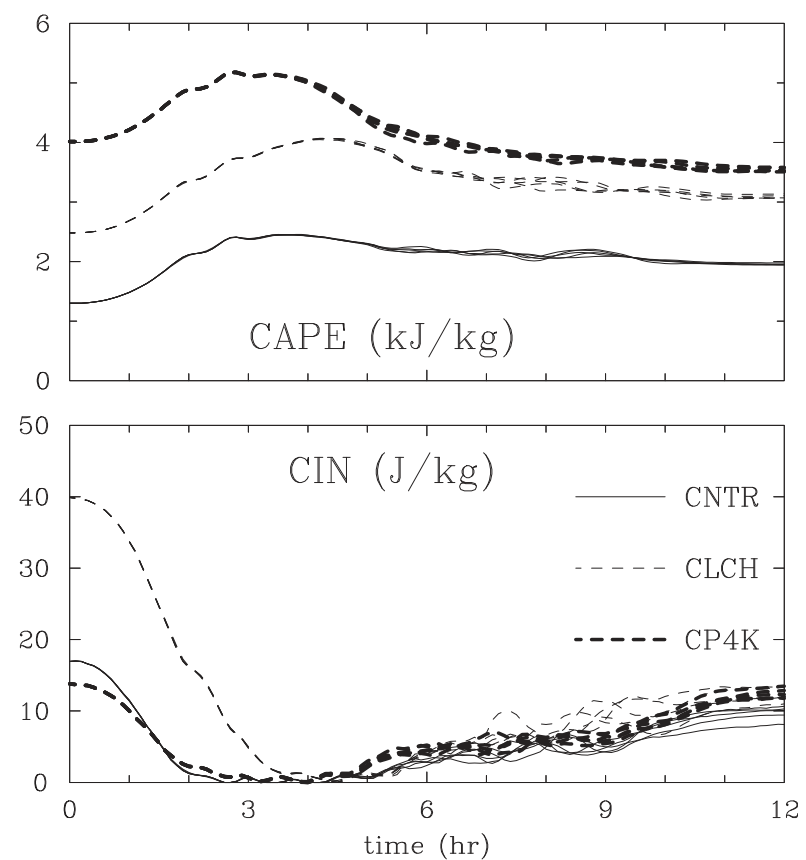

FIG. 3. Evolution of CAPE and CIN in drivers of all simulations (three ensemble members). 
CNTR versus CCRH, hour 6
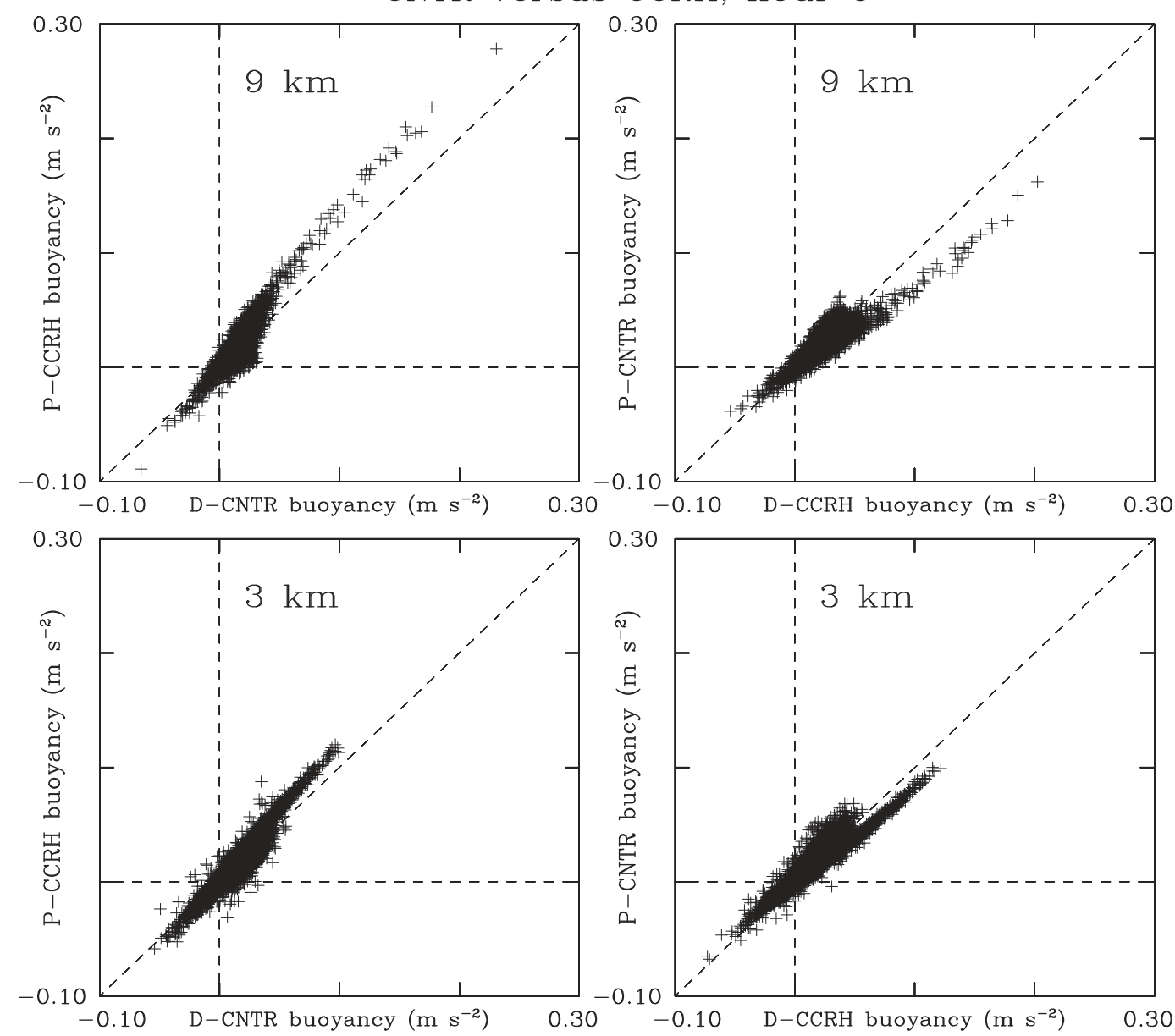

FIG. 4. Point-by-point comparison of the in-cloud buoyancy for the driver vs the piggybacker for randomly selected members of the CNTR/CCRH ensemble simulations. (left) CNTR drives; (right) CCRH drives. (top) Height of $9 \mathrm{~km}$; (bottom) height of $3 \mathrm{~km}$.

high CAPE and low CIN is associated with the increase of the mean cloud width and thus reduced bulk entrainment. This allows for a gradual increase of individual cloud vertical development (see, e.g., Fig. 16 in Kurowski et al. 2018). CAPE decreases gradually and CIN slowly builds up during the second half of the simulations.

\section{b. Cloud buoyancy and updraft statistics}

CAPE differences between CNTR, CLCH, and CCRH suggest a significant contrast in the convective dynamics, especially in the upper troposphere as this is where the differences in the pseudoadiabatic parcel buoyancy are the largest (cf. Fig. 2). However, CAPE is based on the adiabatic parcel and thus excludes realistic variability of cloud buoyancy that is affected by entrainment, condensate loading, precipitation, etc. The piggybacking methodology allows point-by-point comparison of in-cloud buoyancies between the driver and piggybacker. Figures 4 and 5 show scatterplots of the buoyancy from the piggybacker versus the driver buoyancy at the time around the maximum convection strength (sixth hour of the simulation) of the CNTR/ $\mathrm{CCRH}$ and CNTR/CLCH simulations, respectively. Data for cloudy points (sum of cloud and precipitation mixing ratios larger than $0.1 \mathrm{~g} \mathrm{~kg}^{-1}$ ) from randomly selected ensemble member at the height of 3 and $9 \mathrm{~km}$ heights are used. The $3-\mathrm{km}$ height is below the freezing level where warm-rain processes are active, whereas ice processes dominate at the 9-km height. These levels were considered in the previous study of Grabowski and Morrison 2016 (cf. Fig. 8 therein).

For CNTR/CCRH simulations (Fig. 4), the CCRH buoyancies are larger than CNTR regardless whether $\mathrm{CCRH}$ drives or piggybacks the simulation. As suggested by the pseudoadiabatic buoyancies (cf. Fig. 2), the CCRH - CNTR differences are larger in the upper 

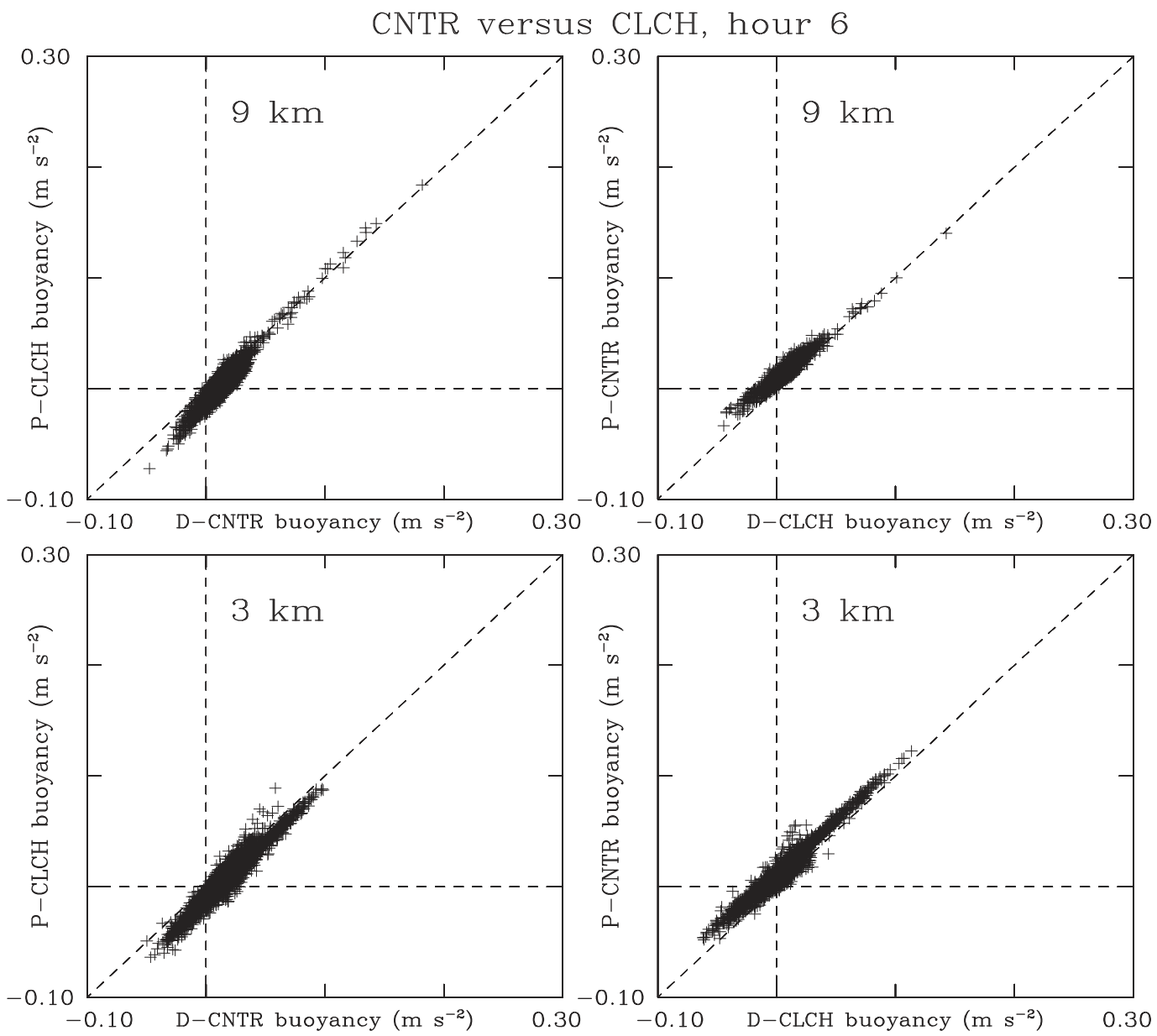

FIG. 5. As in Fig. 4, but for CNTR/CLCH simulations.

troposphere. Although the differences may seem small, these lead to significant differences in the updraft statistics as documented in Fig. 6. The driver-piggybacker differences are much smaller for the CNTR/CLCH simulation, Fig. 5. In fact, there is almost no difference between CNTR and CLCH buoyancies despite significant differences in CAPE (Fig. 2). Arguably, this is because of the impact of lower environmental relative humidity in CLCH on the cloud buoyancy and thus on the convective dynamics. For instance, Derbyshire et al. (2004) showed that the free-tropospheric humidity has a profound impact on moist convection, with deep unorganized convection becoming shallow when the free-tropospheric humidity is reduced from $90 \%$ to $25 \%$. Takemi et al. (2004) used observations from the tropical western Pacific region and idealized model simulations to show that dry layers in the middle and upper troposphere have a more significant impact on convective development than layers with increased static stability.
The differences in the cloud buoyancy directly affect the strength of convective updrafts. This is illustrated in Fig. 6, which shows updraft statistics at 3 and $9 \mathrm{~km}$ and for all model snapshots between hours 6 and 7 of the CNTR, CLCH, and CCRH drivers. In agreement with the buoyancy statistics in Fig. 4, CCRH features the strongest updrafts. Small differences between CNTR and $\mathrm{CLCH}$ are again surprising considering differences in CAPE. However, the differences are consistent with similar CNTR and CLCH cloud buoyancies (cf. Fig. 5), pointing again to the role of environmental freetropospheric humidity in convective dynamics.

\section{c. Evolution of mean cloud field properties}

Figure 7 shows evolutions of ensemble-averaged cloud fraction profiles for all simulations. Cloud fraction at each level is defined as a fraction of grid volumes with the sum of the cloud water mixing ratio and the two ice mixing ratios (i.e., ice mass grown by the diffusion of water vapor and mass grown by riming) larger 


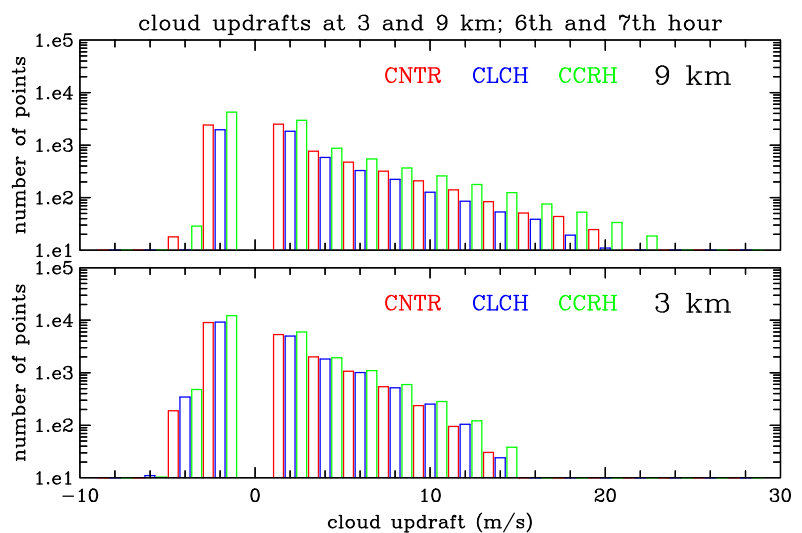

FIG. 6. Histograms of the updraft statistics for drivers in CNTR (red), $\mathrm{CLCH}$ (blue) and CCRH (green) at (top) $9 \mathrm{~km}$ and (bottom) $3 \mathrm{~km}$ for all ensemble members and for 6 th and 7 th hour of the simulations. Histogram bin is $2 \mathrm{~m} \mathrm{~s}^{-1}$. Bins between -2 and $2 \mathrm{~m} \mathrm{~s}^{-1}$ are not shown.

than $0.01 \mathrm{~g} \mathrm{~kg}^{-1}$ as in previous simulations applying the same setup (e.g., Grabowski and Morrison 2016, 2017; Grabowski 2018). Cloud fraction profiles in Fig. 7 show the evolution that is consistent with previous simulations of this case: shallow convection after initial couple hours, transition to deep convection before hour 6 , and only convective anvils with high cloud cover in the final couple hours of the 12-h simulations.

There are systematic differences between the simulations. First, differences between drivers and piggybackers (i.e., solid vs dashed lines) are relatively small until the final couple hours of the simulations. This implies that the thermodynamics (i.e., different amount of water vapor available for convection) is less significant than the dynamics (i.e., different levels of CIN and CAPE). When higher-CAPE sets drive the simulations (i.e., CLCH and CCRH), cloud fields are significantly deeper than when CNTR drives, especially for the highest CAPE CCRH driver. Development of deep convection is delayed in simulations with CLCH driving when comparing to when CNTR drives (upper panels in Fig. 7) in agreement with CAPE and CIN evolutions (Fig. 3).

Cloud fractions, shown in Fig. 7, are larger for CNTR regardless if it is driving or piggybacking the simulation. This seems counterintuitive because both CLCH and CCRH have more water vapor to work with and this should lead to higher cloud fractions. A likely explanation involves the impact of entrainment and detrainment on the cloud field. Assuming that entrainment and detrainment are only weakly affected by the differences in the thermodynamics, similar environmental relative humidity between CNTR and CLCH (and the same for CNTR and CCRH) implies larger saturation deficit (i.e., the difference in the mixing ratios) between a cloud and its environment. This suggests that more cloud water (or ice in the case of anvils) needs to evaporate (sublimate) when entrainment/detrainment takes place to bring the air near the cloud close to saturation. Such an explanation is supported by the analysis of the mean cloud width that can be derived applying a simple algorithm introduced in the appendix of Grabowski et al. (2011) or a more cumbersome method applied in Grabowski et al. (2006; section 3b and Fig. 7 therein). Such an analysis shows that the reduced cloud fractions for shallow clouds early in the simulations as well as for the anvils are associated with reduced cloud widths in both CCRH and CLCH simulations (not shown). The reduced lowlevel humidity in CLCH (cf. Fig. 1) implies that shallow convection develops later than in CNTR as the convective boundary layer has to become deeper for the air from near the surface to reach the lifting condensation level (LCL). This is also why there are no clouds at hour 2 for CLCH driving or piggybacking. The initial relative humidity difference between CNTR and CLCH also implies that the LCL is slightly higher for CLCH at later times, an aspect to be discussed in more detail in section 4.

Figure 8 shows ensemble- and domain-averaged evolutions of the precipitable water (PW), cloud water path (CWP), rainwater path (RWP), ice grown by diffusion water path (DIWP), and ice grown by riming (i.e., accretion of supercooled liquid water) path (RIWP) for CNTR/CLCH simulations. These variables are defined as vertical integrals of the water vapor, cloud water, rainwater, and the two ice water contents predicted by the model. Results from CNTR/CCRH ensembles are similar and thus they are not shown. Overall, the corresponding left and right panels (i.e., the left and right PW panels, left and right CWP panels) are similar. This implies small cloud dynamics differences between CNTR and CLCH, in agreement with cloud buoyancy and updraft statistics (see Figs. 5 and 6). This is also consistent with similar driver-piggybacker differences between the left and right panels. Precipitable water increases over the 12 -h simulations, implying that not all the increase of the atmospheric water vapor due to surface latent heat flux is converted to surface precipitation. The mean cloud water path is larger for CNTR regardless whether it drives or piggybacks in agreement with the cloud fraction profiles (Fig. 7). In contrast, the mean rainwater path is larger for CLCH regardless if $\mathrm{CLCH}$ serves as the driver or piggybacker. The differences between drivers and the driverpiggybacker differences for the two ice water paths are small despite deeper anvils in $\mathrm{CLCH}$ as shown in Fig. 7. This also makes sense as the convective transports are 

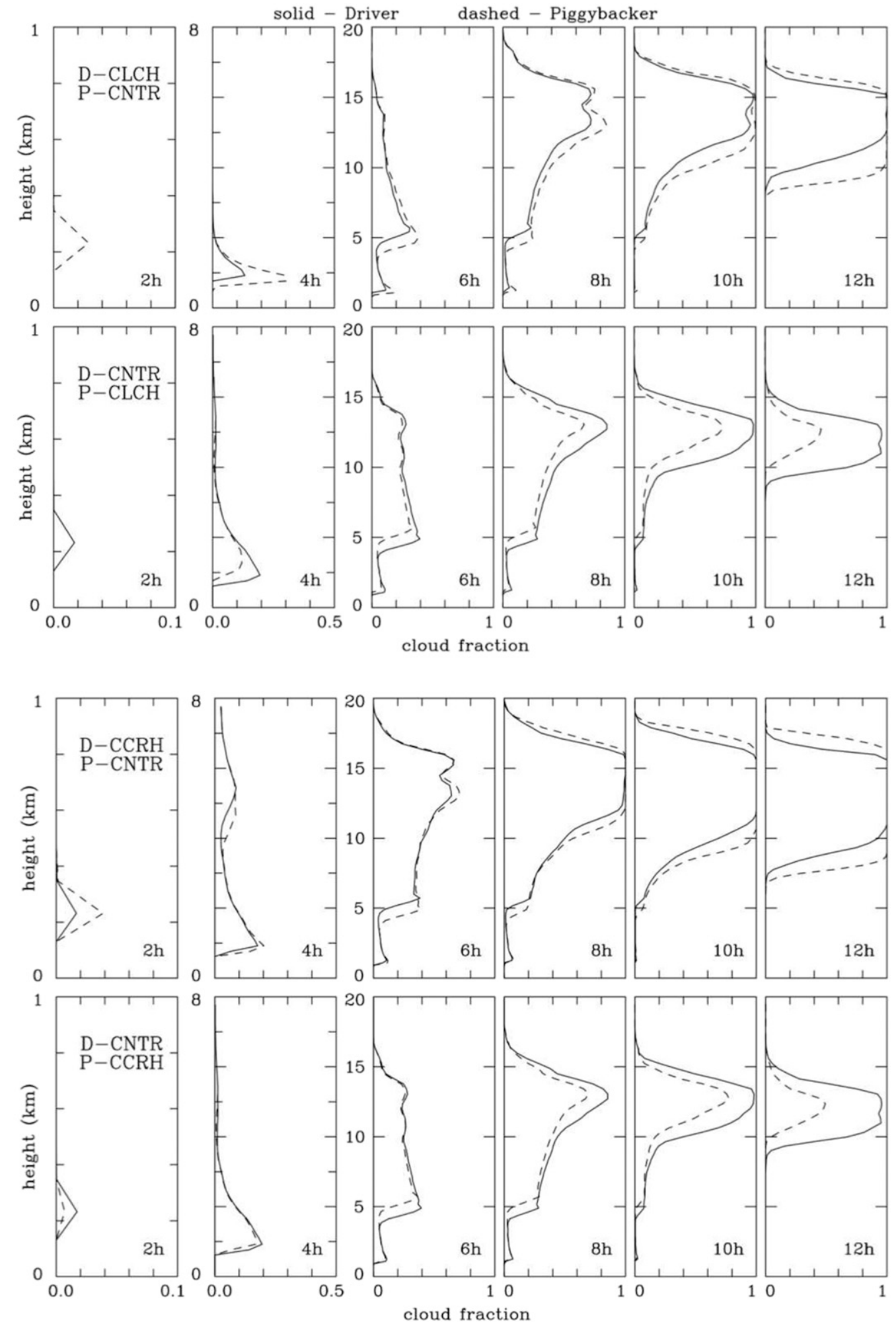

FIG. 7. Evolution of cloud fraction profiles averaged over all ensemble members for (top two rows) CNTR/ $\mathrm{CCRH}$ and (bottom two rows) CNTR/CLCH simulations. Rows from bottom to top show profiles from D-CNTR/P-CCRH, D-CCRH/P-CNTR, D-CNTR/P-CLCH, and D-CLCH/P-CNTR, respectively. Profiles are shown for hours $2,4,6,8,10$, and 12 . The vertical scale is $1 \mathrm{~km}$ for hour $2,8 \mathrm{~km}$ for hour 4 , and $20 \mathrm{~km}$ for hours 6 , 8,10 , and 12 . Solid/dashed lines are for drivers/piggybackers $(\mathrm{D} / \mathrm{P})$. 

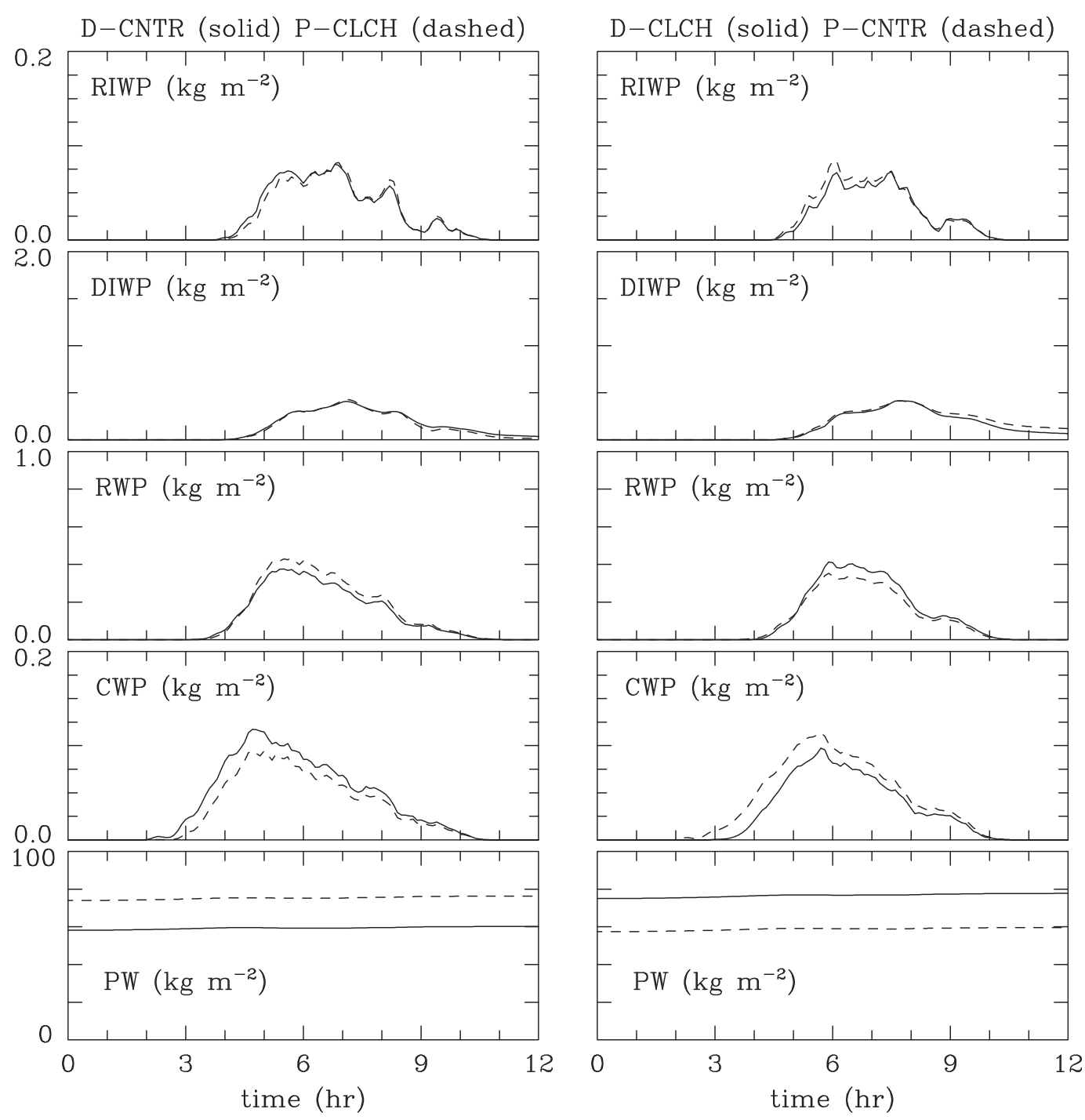

FIG. 8. Evolutions of domain-averaged (from bottom to top) precipitable water (PW), cloud water path (CWP), rainwater path (RWP), diffusion-grown ice water path (DIWP), and rimed ice water path (RIWP) averaged over all CNTR/CLCH ensemble members, showing (left) D-CNTR/P-CLCH and (right) D-CLCH/P-CNTR results. Driver (piggybacker) evolutions are shown by solid (dashed) lines.

similar in CNTR and CLCH (Fig. 6) and thus a similar total mass of the ice field is simply distributed over deeper atmospheric layer in CLCH. For the CNTR/CCRH simulations, there is a noticeable increase of the mean cloud, rain, and ice paths when CCRH drives (not shown), in agreement with the increased convective transport compared to CNTR.

\section{d. Surface rain accumulations}

Surface rain accumulation and its modification is one of the foci of climate change studies (e.g., Alexander et al. 2006; O'Gorman and Schneider 2009; Prein et al. 2017a,b). The piggybacking method allows confident assessment of the convective precipitation alteration that would be otherwise difficult because of nonlinear fluid dynamics leading to highly variable cloud-scale flow and resulting precipitation.

Figure 9 shows statistics of the domain-averaged surface rain accumulations for CNTR/CLCH and CNTR/ $\mathrm{CCRH}$ ensembles. CCRH features slightly more rain independent whether it drives or piggybacks. The mean difference between the drivers (i.e., in the panel marked " $<$ D-CCRH $>$ minus $<$ D-CNTR $>$ ") documents the accumulation increase of about $0.15 \mathrm{~mm}$ from about $2.75 \mathrm{~mm}$ for CNTR (i.e., about a $5 \%$ increase). This corresponds to about a quarter of the Clausius-Clapeyron 

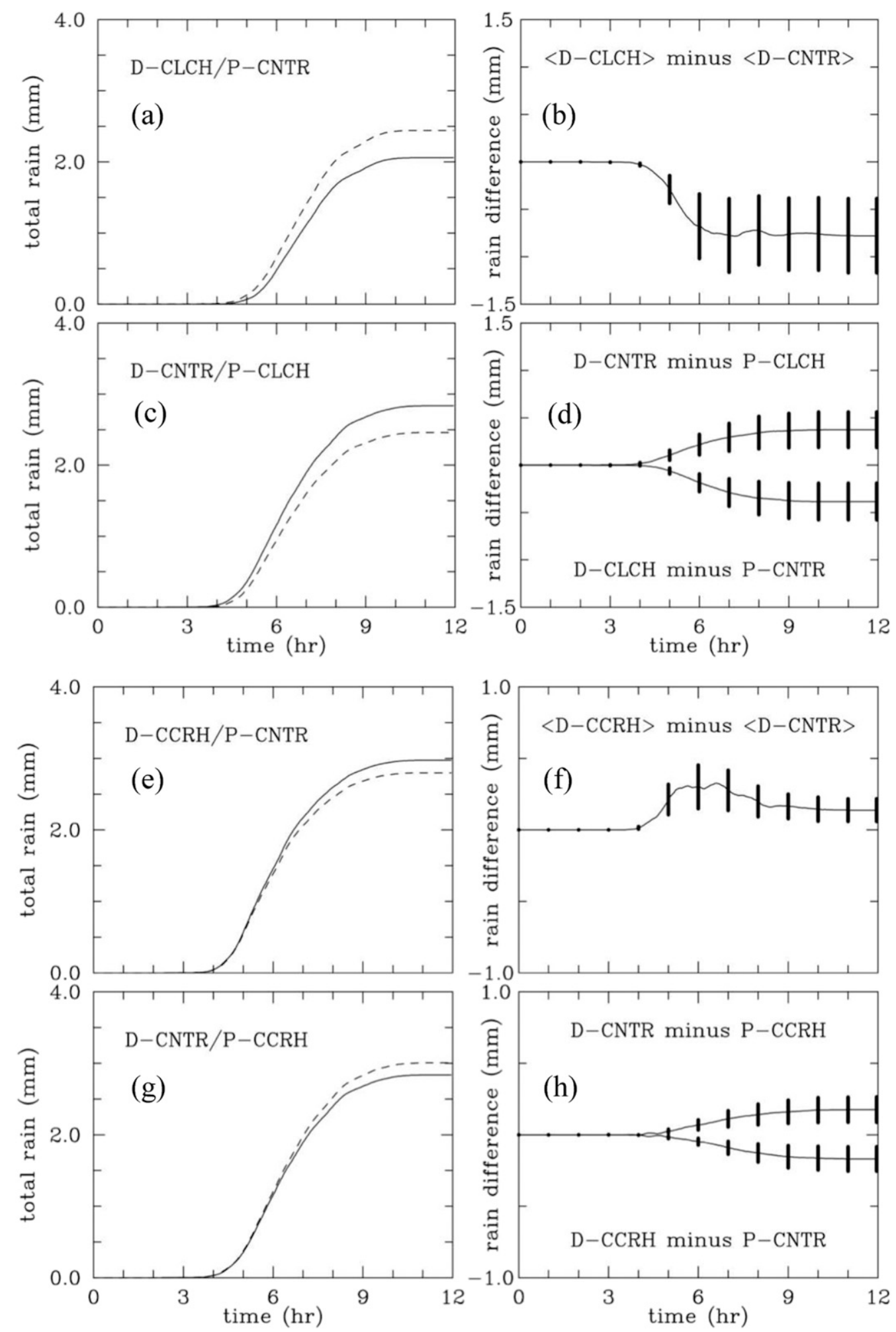

FIG. 9. Evolution of surface rainfall for (a)-(d) CNTR/CLCH and (e)-(h) CNTR/CCRH simulations. (left) Evolutions of ensemble averaged surface rain accumulations in drivers (solid lines) and piggybackers (dashed lines). Note that (b) and (f) show the ensemble averaged difference between the drivers; (d) and (h) show ensemble averaged difference between drivers and piggybackers. Vertical lines in the right panels represent twice the ensemble spread. Note different vertical scales in the right panels between CNTR/CCRH and CNTR/ CLCH simulations. 
scaling. The ensemble mean $\mathrm{D}-\mathrm{P}$ difference is approximately the same when $\mathrm{CCRH}$ is driving and when it is piggybacking. This may be considered surprising because modified cloud dynamics resulted in an altered $\mathrm{D}-\mathrm{P}$ difference in previous applications of the piggybacking method (see Grabowski and Morrison 2016, 2017). For the CNTR/CLCH ensemble, CLCH features less rain accumulation and similar $\mathrm{D}-\mathrm{P}$ differences between $\mathrm{CLCH}$ driving and piggybacking. This again is surprising as $\mathrm{CLCH}$ still has significantly more precipitable water and it arguably comes from reduced low-level humidity that leads to the enhanced rain evaporation below the cloud base.

Figures 10 and 11 show surface maps of 12 -h rain accumulations in randomly selected members of the CNTR/CCRH and CNTR/CLCH ensembles, respectively. The rain accumulation is dominated by the deep convection rainfall and thus changes in the maps between the four drivers (i.e., left panels in Figs. 10 and 11) represent effects of intrinsic variability of convective rainfall. For the CNTR/CCRH simulations (Fig. 10), the spatial pattern of the $\mathrm{D}-\mathrm{P}$ difference (right panels) is spotty and it combines a mixture of positive and negative values regardless which set drives the simulation. This leads to a small increase in the domain-averaged accumulation in CCRH as shown in Fig. 9. In contrast, the pattern for CNTR/CLCH (Fig. 11) is negative (positive) when CLCH (CNTR) drives the simulation. The overall result is more averaged accumulation for the CNTR as shown in Fig. 9.

Results from Figs. 10 and 11 are combined with all other ensemble members and presented in the form of scatterplots in Fig. 12. The figure shows the point-bypoint $\mathrm{D}-\mathrm{P}$ difference of the surface rain accumulation as a function of the driver rain accumulation. Dashed lines in the figure are the linear least-squared fits to the data points. In general, there is a significant scatter of the data points, so the impact of the modified soundings in $\mathrm{CCRH}$ and CLCH is complex. For CCRH, the dashedline slope is about $4 \%$ when CNTR drives and about $5 \%$ when CCRH drives (i.e., around $1 \% \mathrm{~K}^{-1}$ of the temperature increase). This is significantly smaller than the Clausius-Clapeyron scaling. The slopes are larger for CNTR/CLCH, but they show the opposite effect, that is, the reduction of the mean surface rain for CLCH.

The data shown in Fig. 12 represent point-by-point analysis of the surface rainfall that is only possible through the piggybacking methodology. However, previous analyses of the climate change impact on the surface rainfall typically investigate surface hourly precipitation on a percentile basis (Ban et al. 2015; Schär et al. 2016; Prein et al. 2017b). Following those previous studies, Fig. 13 shows hourly precipitation differences on a percentile basis since climate change effects can be rainfall intensity dependent (e.g., Ban et al. 2015; Prein et al. 2017b). Therefore, percentile values in $0.01 \%$ increments are calculated from the zeroth to the 99.99th percentile including hours without surface rain. Those percentiles are then compared between the current and future climate simulation. In contrast to the results in Fig. 12, this analysis does not depend on the location of rainfall but only on its frequency and intensity within the simulation domain.

Precipitation rates below $70 \mathrm{~mm} \mathrm{~h}^{-1}$ decrease between $14 \%$ and $20 \%$ in the D-CNTR/P-CLCH simulations whereas rainfall rates larger than $120 \mathrm{~mm} \mathrm{~h}^{-1}$ decrease by less than $10 \%$ (Fig. 13a). This is different from the expected heavy precipitation increases according to the Clausius-Clapeyron relationship. Switching to D-CLCH/P-CNTR leads to generally less intense precipitation but shows overall similar decreases in the future rainfall rates (Fig. 13b). The asymmetry between the D-CNTR/P-CLCH and D-CLCH/P-CNTR results indicates that storm-scale dynamics also have an effect on precipitation changes. Comparing the independent D-CNTR to the D-CLCH simulation (Fig. 13c) shows that weak rainfall rates $\left(<10 \mathrm{~mm} \mathrm{~h}^{-1}\right)$ decrease by more than $30 \%$. Heavy precipitation rates decrease less and the three ensemble members show a spread from $-10 \%$ to $-20 \%$.

Hourly precipitation changes for the D-CNTR/ P-CCRH simulations show a large increase of weak precipitation rates below $10 \mathrm{~mm} \mathrm{~h}^{-1}$ and approximately $5 \%-10 \%$ increase of rates larger than $50 \mathrm{~mm} \mathrm{~h}^{-1}$ in the future (Fig. 13d). This is much less than the $28 \%$ increase that one would expect from the ClausiusClapeyron scaling under $4^{\circ} \mathrm{C}$ warming. Switching to D-CCRH/P-CNTR (Fig. 13e) leads to similar results. Comparing D-CNTR with D-CCRH (Fig. 13f) shows up to $30 \%$ increases in $\sim 10 \mathrm{~mm} \mathrm{~h}^{-1}$ precipitation rates, decreases of up to $15 \%$ in precipitation rates between 70 and $200 \mathrm{~mm} \mathrm{~h}^{-1}$, and a large spread of projected extreme precipitation rates varying between $-15 \%$ and $14 \%$. These results are contrary to previous studies, which showed that extreme hourly precipitation increases are consistent with or exceed expectations from the Clausius-Clapeyron relationship (e.g., Kendon et al. 2014; Ban et al. 2015; Prein et al. 2017b).

In summary, tropical precipitation from unorganized convection over land might change differently from precipitation in midlatitudes or over tropical ocean regions. A decrease in near-surface relative humidity, which is projected in global climate simulations (Fig. 1a), results in a reduction of precipitation at all rates. Keeping the future relative humidity constant results in moderate increases in precipitation rates. However, these changes 

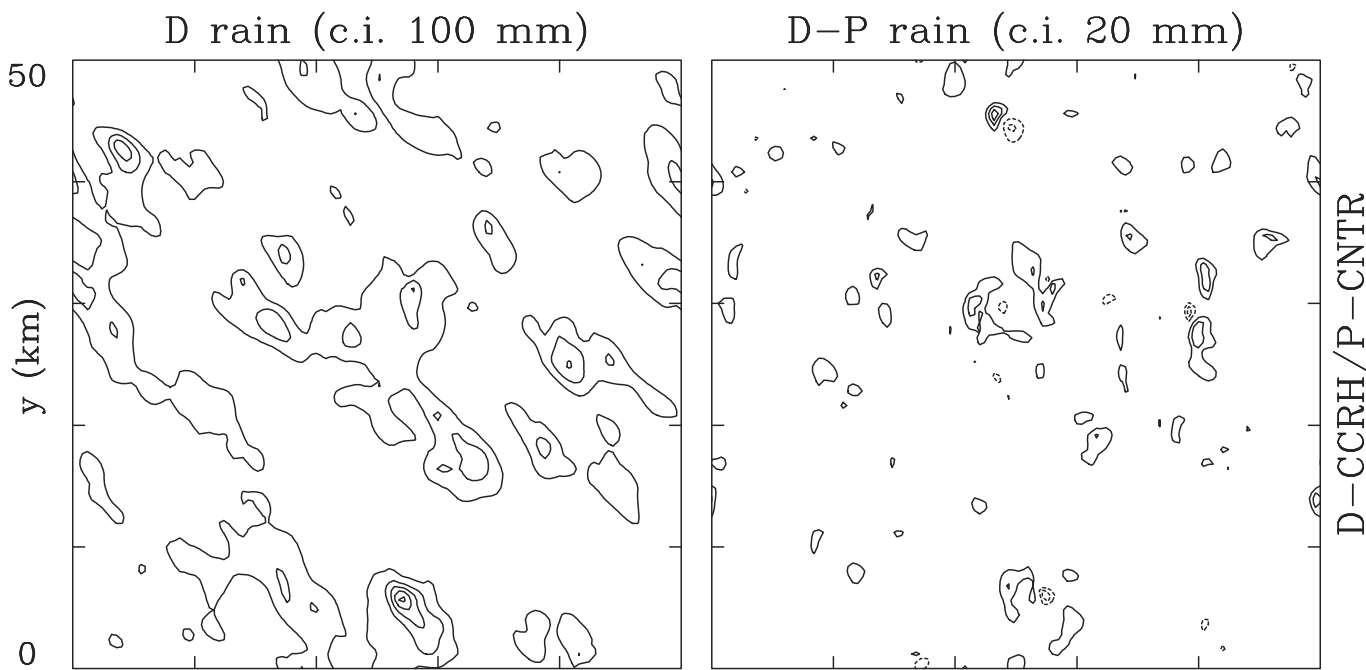

50
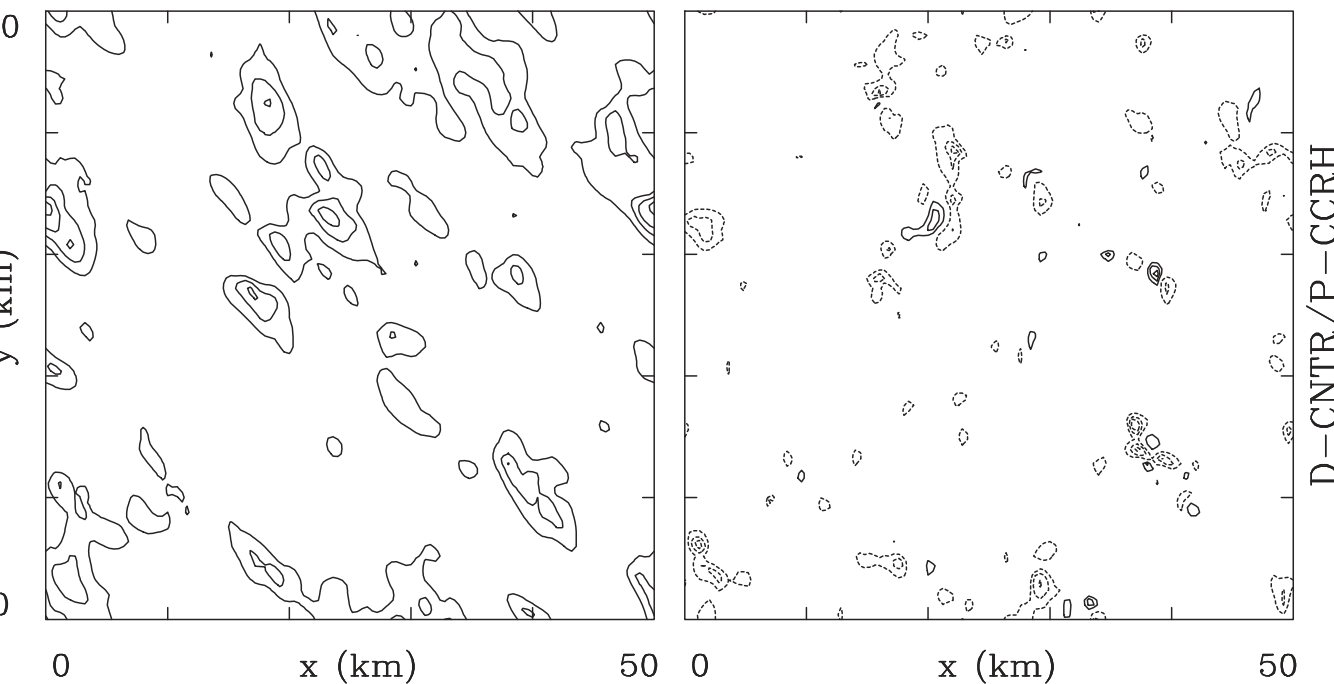

FIG. 10. Spatial distribution of (left) 12-h driver surface rain accumulation and (right) 12-h driver minus piggybacker accumulation difference in two randomly selected members of the CNTR/CCRH ensemble, where (top) CCRG drives and (bottom) CNTR drives. Contour interval is $100 \mathrm{~mm}$ in the left panels and $20 \mathrm{~mm}$ in the right panels.

are far beyond expectations from the Clausius-Clapeyron relationship.

\section{LES simulations}

Evolution of cloud fraction profiles in Fig. 7 suggests that there are significant differences in the development of shallow convection for different initial thermodynamic profiles. However, the simulations discussed above apply relatively coarse horizontal and vertical resolutions from the point of view of boundary layer dynamics and shallow convection. Thus, we decided to run higher-resolution large-eddy simulation (LES)-type piggybacking simulations covering only the initial $4 \mathrm{~h}$ of convective development. These simulations apply a smaller horizontal domain of $12.5 \mathrm{~km} \times 12.5 \mathrm{~km}$ and $100-\mathrm{m}$ horizontal grid length. The 8 -km-deep vertical domain is covered with 81 levels. The stretched vertical grid features vertical grid length of about $50 \mathrm{~m}$ below $500 \mathrm{~m}$, stretching out to about $100 \mathrm{~m}$ at $2 \mathrm{~km}$ and $120 \mathrm{~m}$ at $5 \mathrm{~km}$. The time step is $3 \mathrm{~s}$. Single simulations are used with CNTR/CLCH and CNTR/CCRH piggybacking setups.

Figure 14 shows cloud fraction profiles (calculated as in Fig. 7 for the lower-resolution simulations) for hours 2 , 3 , and 4. Overall, the profiles are consistent with those shown in Fig. 7. For the CCRH/CNTR, the driverpiggybacker differences at hours 2 and 3 involve a slight change of the cloud base height and a significant modification of the cloud fraction. As discussed in section 3 , the cloud fraction difference arguably comes from the 


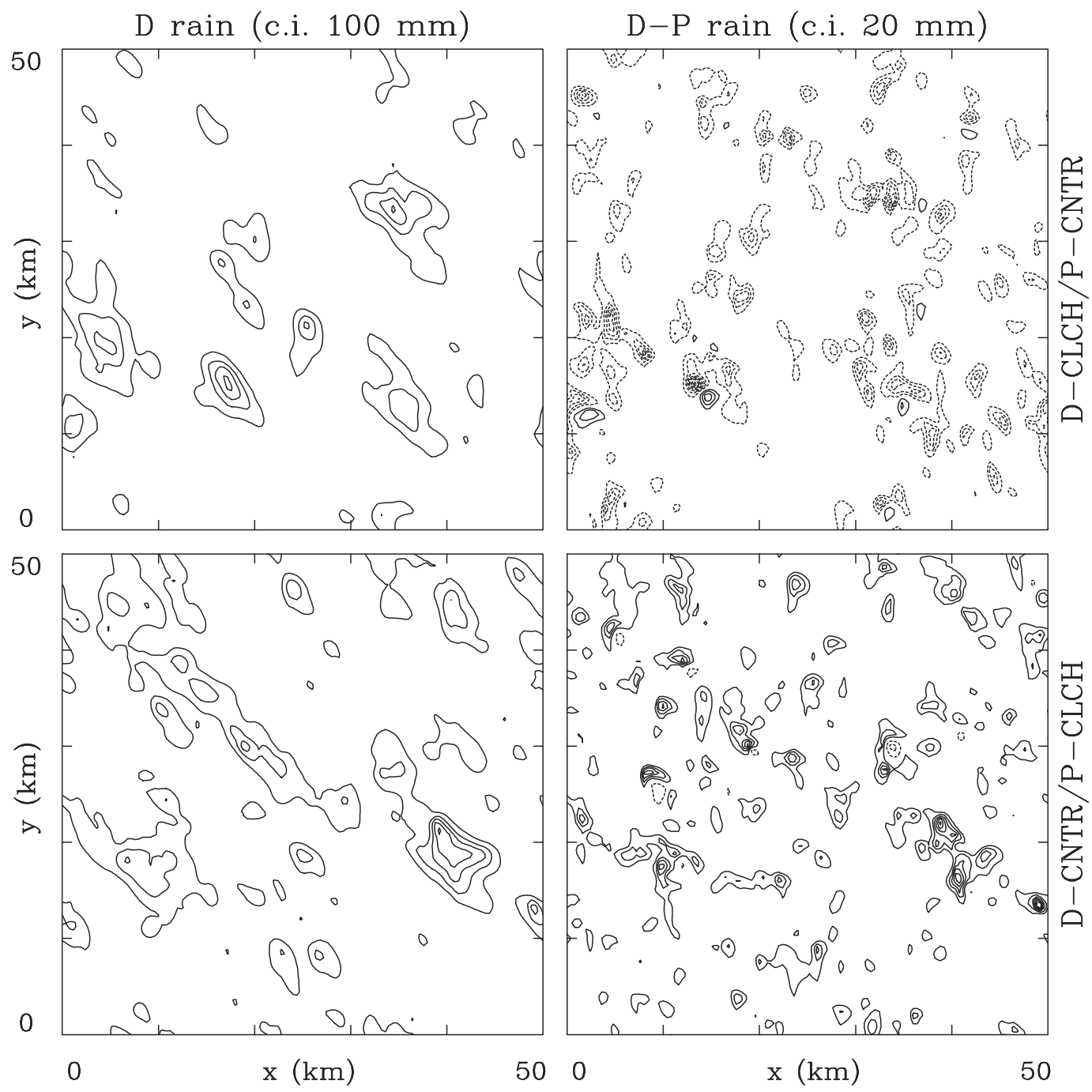

FIG. 11. As in Fig. 10, but for randomly selected members of CNTR/CLCH ensemble.

saturation deficit between CNTR and CCRH (despite the same initial relative humidity) and the saturation deficit impact on the cumulus entrainment/detrainment. For $\mathrm{CNTR/CLCH}$, the differences in shallow convection also involve the impact of the near-surface relative humidity on convective development, especially on the timing when clouds first appear near the top of the convective boundary layer. The change of the cloud base height $\Delta z$ depends on the near-surface relative humidity change $\Delta \mathrm{RH}$ :

$$
\Delta z=\left(\frac{d \mathrm{RH}}{d z}\right)^{-1} \Delta \mathrm{RH}
$$

Assuming the adiabatic lapse rate between the surface and the cloud base and applying the Clausius-Clapeyron formula for the change of the saturated water vapor pressure in $\mathrm{RH}$, one gets

$$
\frac{d \mathrm{RH}}{d z}=\mathrm{RH}^{2} g L_{v} e_{s} /\left(c_{p} R_{v} T^{2}\right)
$$

The near-surface relative humidity change from CNTR to $\mathrm{CCRH}$ is small and it only comes from converting the surface latent heat flux into the water vapor mixing ratio tendency. In a nutshell, the same surface flux leads to a smaller relative humidity change when the initial relative humidity is the same but the temperature is higher. This is because the higher temperature implies larger saturated water vapor mixing ratio. Analysis of the relative humidity in boundary layer eddies with updrafts stronger than $0.5 \mathrm{~m} \mathrm{~s}^{-1}$ at $100 \mathrm{~m}$ above the surface at hours 2 and 3 shows that $\mathrm{CCRH}$ features around $1 \%$ lower relative humidity when compared to CNTR. With about $80 \%$ relative humidity at this height, the expected shift of the cloud base height is about $25 \mathrm{~m}$, smaller than the model vertical grid length near the cloud base. Similar analysis for the CNTR 

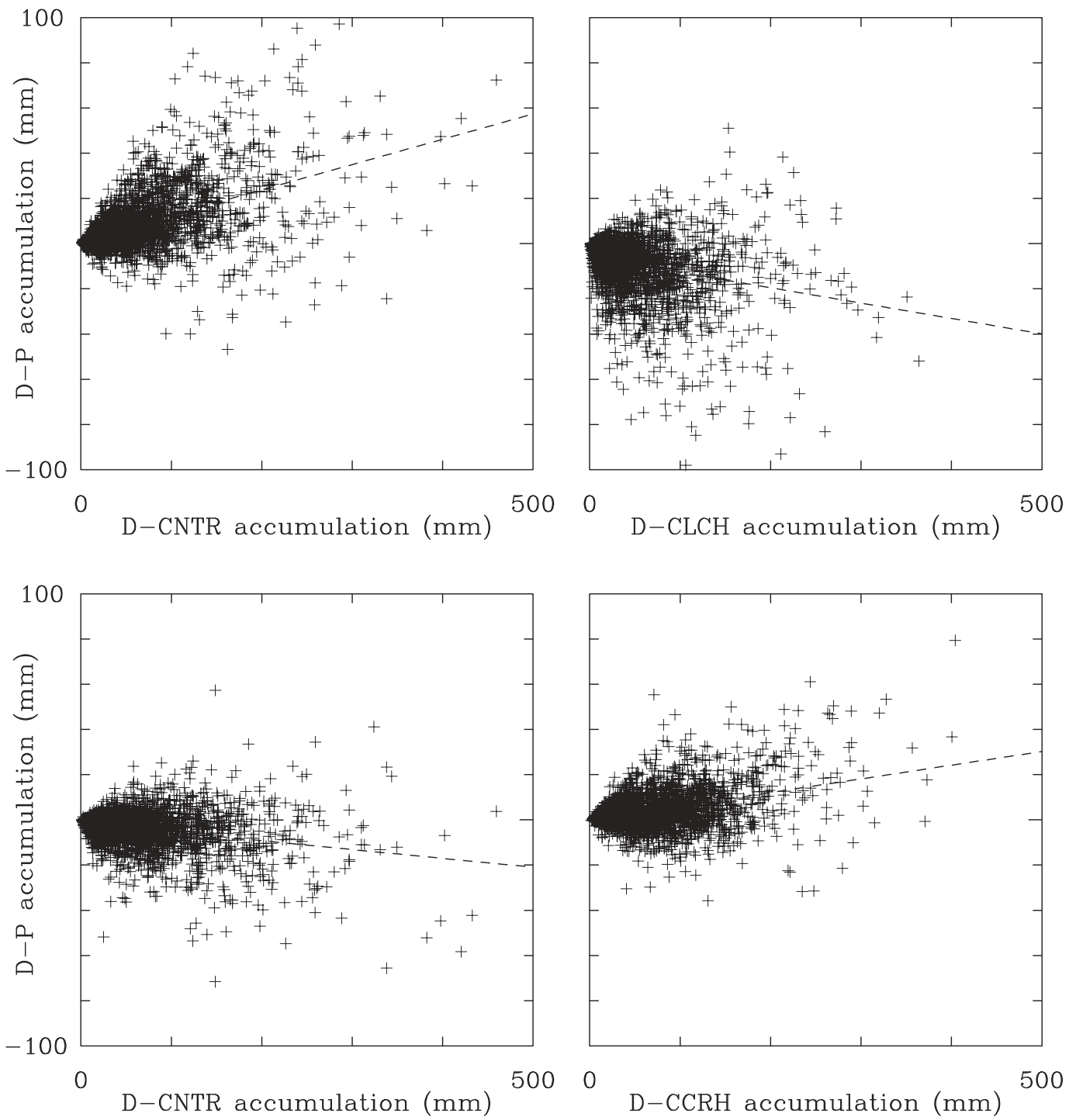

FIG. 12. Scatterplots of the driver minus piggybacker 12-h surface rain accumulation vs driver 12-h rain accumulation for all members of (top) CNTR/CCRH simulations and (bottom) CNTR/CLCH simulations, where (left) CNTR drives and (right) CCRH/CLCH drives. Dashed lines show least-squared fit to the data.

and $\mathrm{CLCH}$ simulations shows about $7 \%$ lower relative humidity for the CLCH simulation at hours 2,3 , and 4 . This translates to about a $180-\mathrm{m}$ difference in the cloud base height in agreement with the profiles shown in Fig. 14: there are no clouds in CLCH at hour 2 with CNTR clouds between 100- and 200-m height, and cloud bases are about $200 \mathrm{~m}$ higher in CLCH at hours 3 and 4.

\section{Discussion and conclusions}

This manuscript discusses results from a pilot study that applies piggybacking modeling methodology to separate dynamical and thermodynamical impacts of climate change on daytime convection development over summertime continents. The dynamical impact concerns modifications of the convection strength resulting from the climate change-induced adjustment of the atmospheric stability. The thermodynamical impacts involve effects of the increased water vapor that the warmer atmosphere can hold and convection can work with. The piggybacking applies two sets of thermodynamic variables in a single cloud field simulation. The first set is coupled to the dynamics and drives the simulation, and the second set follows ("piggybacks") the simulated flow. The driver and piggybacker are swapped in the second simulation. In simulations discussed here, 

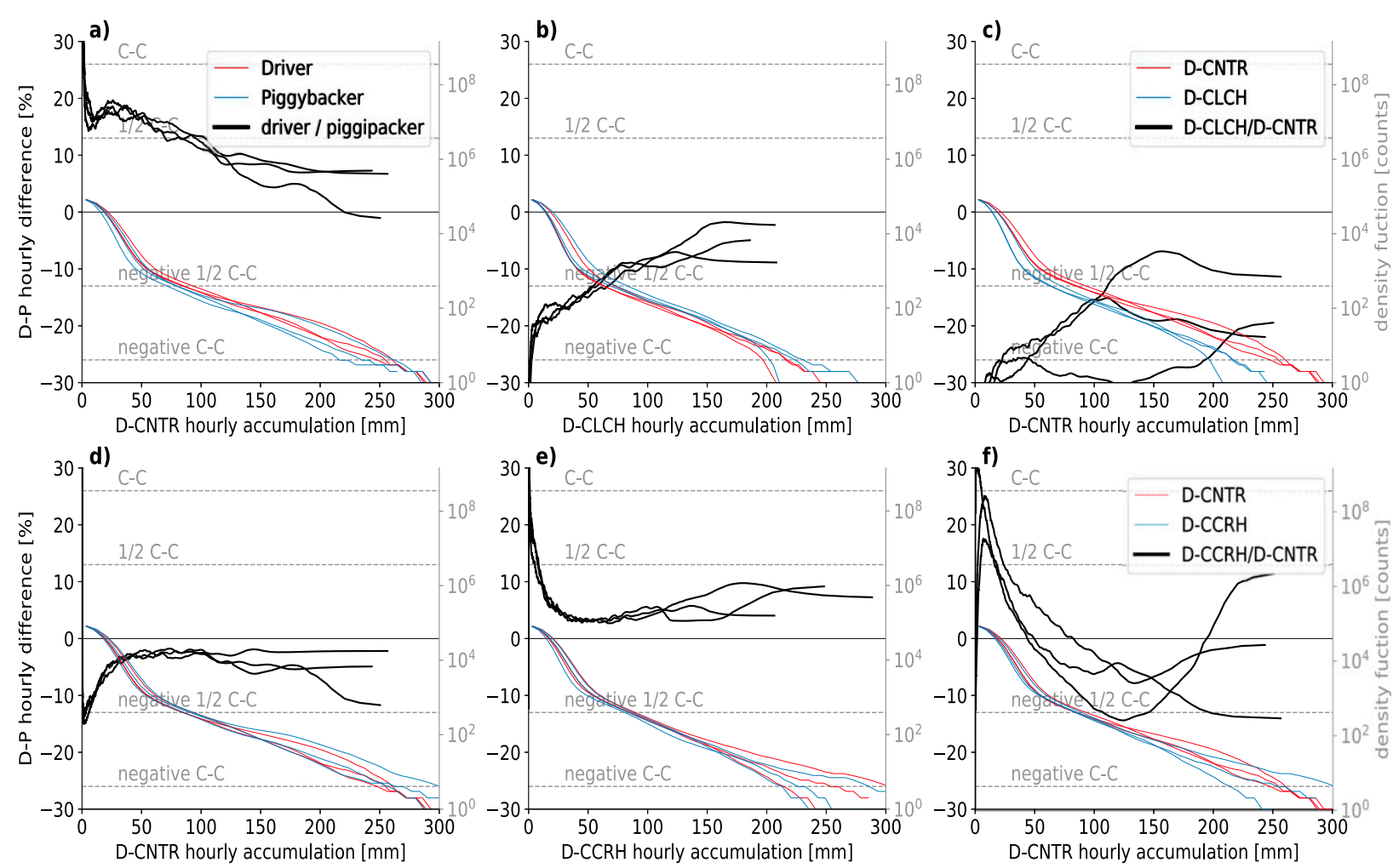

FIG. 13. The thick black lines show (left),(center) percentile differences between driver and piggybacker and (right) current minus future driver hourly surface precipitation accumulations for all members of (a)-(c) CNTR/CLCH and (d)-(f) CTRL/CCRH between simulation hours 3 and 12, where CTRL drives in the left panels and CLCH/CCRH drives in the center panels. Dashed gray lines show expected increases according to the Clausius-Clapeyron (C-C) relationship. The secondary $y$ axis relates to the density functions of hourly accumulated precipitation (colored lines). Only data up to $99.99 \%$ are shown.

the driver-piggybacker differences come from the impact of the thermodynamics, and differences in the drivers reflect the impact of convection strength. The modeling setup is based on observations in the Amazon region and was developed over a decade ago (Grabowski et al. 2006) and has been used in studies concerning convective dynamics (Khairoutdinov and Randall 2006; Wu et al. 2009; Grabowski and Morrison 2017; Kurowski et al. 2018) and microphysics (Grabowski 2015, 2018; Grabowski and Morrison 2016). The simulations are driven by evolving surface sensible and latent heat fluxes that mimic effects of daytime solar insolation on the tropical forest land surface.

We apply the pseudo-global warming methodology (Schär et al. 1996; Kawase et al. 2009; Rasmussen et al. 2011). The setup applying the initial sounding from Grabowski et al. (2006) is referred to as the control (CNTR). The CNTR sounding is modified using mean temperature and moisture changes as predicted by an ensemble of CMIP5 global climate models over the Amazon region (Fig. 1). The modified initial sounding is applied in climate change $(\mathrm{CLCH})$ simulations. It features 4-5-K warmer low and middle troposphere and $5 \%-10 \%$ lower relative humidity; see Fig. 1 . For comparison, we also include simulations with the initial sounding featuring the same temperature change as in CLCH but unchanged relative humidity, that is, featuring a moisture increase following exactly the Clausius-Clapeyron scaling. This sounding is referred to as CCRH ("climate change with the same RH"). CNTR and $\mathrm{CLCH}$ conditions are contrasted in the first set of piggybacking simulations with CNTR driving and CLCH piggybacking in one three-member mini-ensemble (referred to as D-CNTR/P-CLCH) and then CLCH driving and CNTR piggybacking in the second mini-ensemble (D-CLCH/P-CNTR). CNTR and CCRH are contrasted in the second set of simulations including D-CNTR/ $\mathrm{P}-\mathrm{CCRH}$ three-member mini-ensemble and D-CCRH/ P-CNTR mini-ensemble. The focus is on the driver minus piggybacker $(\mathrm{D}-\mathrm{P})$ comparison, often grid point by grid point (e.g., Figs. 4, 5, 9-11). Without piggybacking, details of the climate change impact on convection can only be studied by applying conditional sampling of a sufficiently large simulation ensemble to separate natural variability 

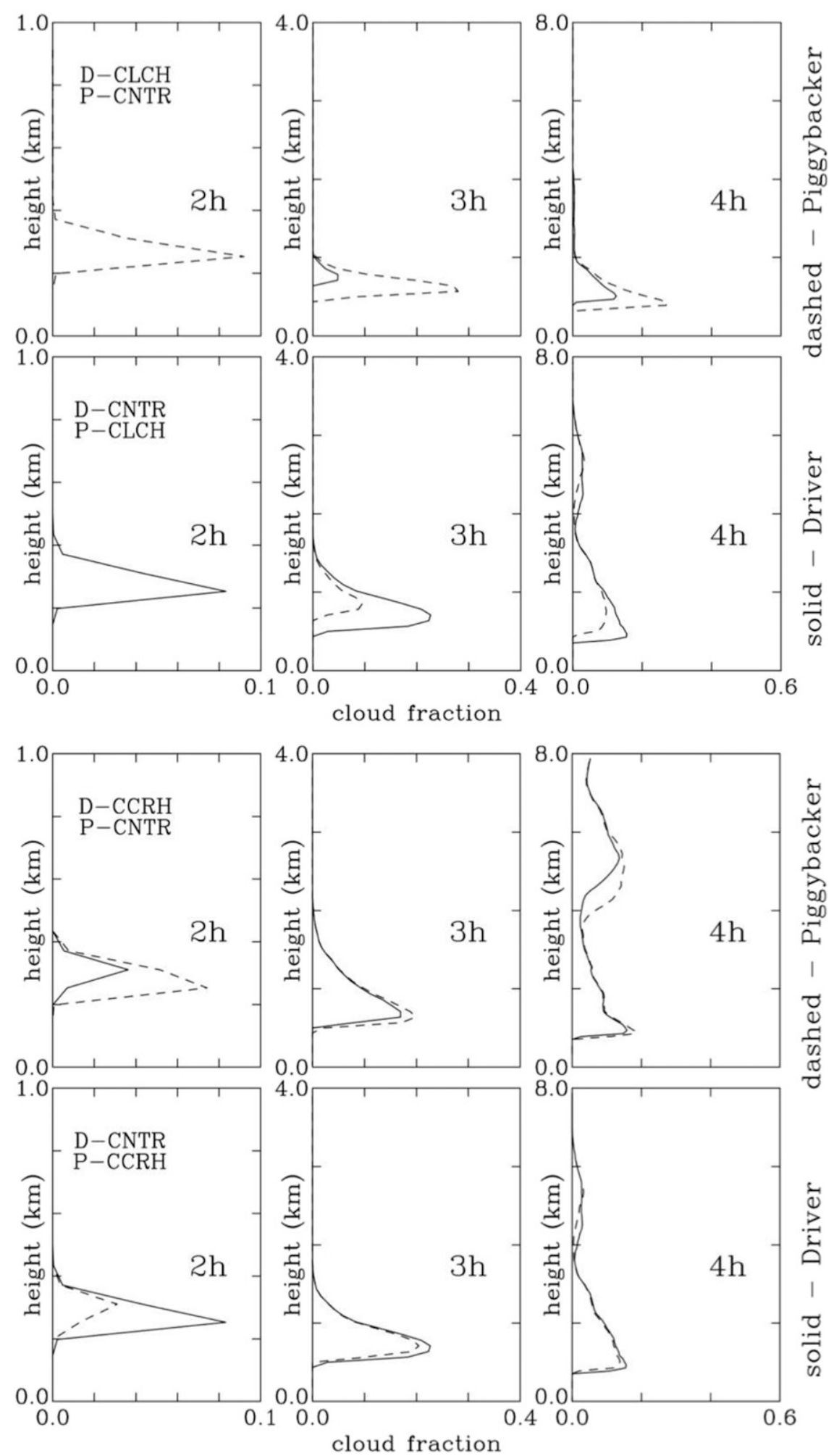

FIG. 14. As in Fig. 7, but for hours 2, 3, and 4 in LES simulations. The vertical scale is $1 \mathrm{~km}$ for hour 2, $4 \mathrm{~km}$ for hour 3 , and $8 \mathrm{~km}$ for hour 4 . 
of convection (i.e., different flow realizations) from the impact of a physical process or its parameterization.

The simulations clearly show that the simulated impact of climate change on convection is dominated by cloud dynamics, and not by the cloud thermodynamics. The initial CLCH and CCRH soundings feature significantly larger CAPE and higher neutral buoyancy levels than CNTR (see Fig. 2). However, relatively small initial $\mathrm{RH}$ difference between $\mathrm{CLCH}$ and CCRH has a significant impact on the simulations, arguably because of the RH impact on convective dynamics through entrainment (e.g., Derbyshire et al. 2004; Takemi et al. 2004). In essence, entraining drier environmental air more significantly reduces cloud buoyancy. As a result, CNTR and CLCH feature similar in-cloud buoyancies (Fig. 5), updrafts (Fig. 6), and condensed water paths (Fig. 8). However, the cloud mass is distributed over a deeper layer in agreement with the higher level of neutral buoyancy in CLCH. This leads to a vertically extended cloud fraction profiles when CLCH drives the simulation (Fig. 7). Rain accumulations are significantly reduced in CLCH when compared to CNTR $(10 \%-$ $15 \%)$, that is, in the opposite direction than the increase in the atmospheric moisture (cf. Fig. 1). In simulations where the modified climate-change temperature signal is accompanied by the unchanged RH (the CCRH miniensembles), noticeable increases of the cloud buoyancy, updraft strength, cloud fraction, and surface rain accumulation are simulated. Rain accumulation increases by about $5 \%$ between CNTR and CCRH, which is in line with the $1 \%-2 \% \mathrm{~K}^{-1}$ warming global average precipitation increase predicted by global climate models (Allen and Ingram 2002; Trenberth et al. 2003).

Differences between driver and piggybacker are relatively small in all simulations. This highlights a relatively small effect of the increased water vapor available for convection in the climate change simulations discussed here. However, there are interesting thermodynamic effects that warrant further investigations, like the reduction of cloud fractions even if the relative humidity is kept constant (CCRH simulations; Fig. 7) or delay of the shallow convection development when lower-tropospheric humidity is reduced in $\mathrm{CLCH}$ (Fig. 14). We argue that the former comes from the increased saturation deficit (i.e., the difference of the water vapor mixing ratio between a shallow cumulus cloud and its environment) in higher temperatures even with unchanged environmental RH. This implies that more cloud needs to evaporate to keep the immediate cloud environment close to saturation. The reduction of saturation deficit with the same $\mathrm{RH}$ in a warmer climate can also explain reduced cloud fractions of the upper tropospheric anvils in CNTR/CCRH ensembles (lower two rows in Fig. 7). Previous work investigating climate change effects on saturation deficits mainly focuses on tropical cyclones and shows that an increasing deficit could lead to a suppression of tropical cyclone genesis (Knutson et al. 2010; L. Zhang et al. 2017). For CLCH simulations, changes during shallow convection phase can be explained by the increase of the lifting condensation level when surface relative humidity is reduced (see section 4). For the CLCH anvils, differences during the last few hours (Fig. 7) can be explained by the reduced upper tropospheric relative humidity (as shown in Fig. 1) in addition to the saturation deficit difference.

The impact on surface rainfall is perhaps the most surprising. The average 12-h accumulation (Fig. 9) is only slightly larger for CCRH and it is significantly smaller in CLCH when compared to CNTR. This is regardless of whether CCRH/CLCH drives or piggybacks the simulation. These impacts seem consistent with the changes (for $\mathrm{CCRH}$; or lack thereof for $\mathrm{CLCH}$ ) of convective dynamics combined with the changes (for $\mathrm{CLCH}$, or lack thereof for CCRH) of near-surface RH. The averaged low-level RH is about $10 \%$ lower in CLCH and this seems to be the deciding factor, perhaps highlighting the role of rain evaporation below the cloud base. Figures 10 and 11 show how the 12-h D - P accumulation spatial distributions-possible to derive only in piggybacking simulations - translate into mean rain accumulation differences. Previous studies that use convection-permitting models show that extreme precipitation rates are more likely to increase according to Clausius-Clapeyron expectations than moderate or weak rates (e.g., Muller and O'Gorman 2011; Ban et al. 2015; Prein et al. 2017b; Ban et al. 2018). Concerning model resolution and setup, our study is more comparable to that of Romps (2011), who also shows close to Clausius-Clapeyron increases in precipitation fluxes. In our simulations, hourly precipitation extremes decrease in the CLCH simulations and only slightly increase in the CCRH simulations (Fig. 13). The exact reasons for the lower increases/decreases of extreme precipitation are unclear and should be the subject of future investigations.

These results indicate that climate change on precipitation might strongly depend on the mode of convection. Here we simulate unorganized tropical convection in weakly sheared environments. Prein et al. (2017a) show that extreme hourly precipitation in organized convection in the form of mesoscale convective systems is increasing by $\sim 7 \% \mathrm{~K}^{-1}$ warming and that the area of heavy rainfall in these systems is up to doubling. These changes occur besides a slight decrease in relative humidly in the lowest $12 \mathrm{~km}$ of the atmosphere. We expect that application of the piggybacking simulation method 
to organized convection simulations in the future will allow improved understanding of dynamical and thermodynamical impacts of climate change on the organized deep convection.

One of the key findings of this study is the strong sensitivity of tropical deep convection to changes in environmental humidity. Although the initial sounding of the CLCH and CCRH simulations only differ by $3 \mathrm{~kg} \mathrm{~m}^{2}$ in precipitable water $\left(73 \mathrm{vs} 76 \mathrm{~kg} \mathrm{~m}^{2}\right)$ the resulting deep convection development and surface precipitation accumulations differ substantially. This is concerning since future projections of $\mathrm{RH}$ changes over land are uncertain (Laîné et al. 2014) and vary between no changes and $-20 \%$ in GCM simulations at the Amazon sounding location (see Fig. 1a). Constraining climate change-induced uncertainties in low-level humidity seems to be essential to enhance our understanding of how deep convection and warm season surface precipitation change in the future.

This study poses several questions that suggest followup investigations.

- For the modeling setup, how realistic is the assumption of the same surface sensible and latent heat fluxes in the climate change environment? This concerns not only the total flux but also its partitioning into sensible and latent components, which depends on the surface energy and water budgets. The partitioning significantly affects daytime convective development over land because it affects the surface buoyancy flux and boundary layer evolution (e.g., Thomas et al. 2018).

- What is the sensitivity of model results discussed here to the representation of cloud microphysics?

- Is taking the mean profiles a meaningful approach? How much would results change if one takes not the mean climate change signal from several models, but the signal from each climate model separately? The changes in the atmospheric temperature and moisture profiles in each climate model come from a web of forcing and feedbacks between atmospheric and land surface processes that each model represents in a unique way.

- How realistic are the dramatic changes in the uppertropospheric cloudiness simulated by the cloud-scale model from the climate perspective? Clouds strongly affect the surface energy budget and in turn the magnitude of surface energy fluxes. One possibility would be to extend the setup of Grabowski et al. (2006) into longer simulations (say, a few days or a couple weeks) and include a simple surface energy budget scheme responding to changes in cloudiness. Simulation applying such a framework would provide answers to some of the above questions.
We hope to report some of such simulations in the future.

Acknowledgments. WWG acknowledges partial supported from the U.S. DOE ASR Grant DE-SC0016476 and by the National Center of Meteorology, Abu Dhabi, UAE, under the UAE Research Program for Rain Enhancement Science (project UAE_NATURE). Any opinions, findings, and conclusions or recommendations expressed in this material are those of the author(s) and do not necessarily reflect the views of the National Center of Meteorology, Abu Dhabi, UAE. NCAR is sponsored by the National Science Foundation.

\section{APPENDIX}

\section{The Piggybacking Approach}

Figure A1 illustrates the piggybacking approach. The crux of the approach is to apply two sets of thermodynamic variables (the potential temperature $\Theta$, water vapor mixing ratio $q_{v}$, and all variables describing aerosol, cloud $q_{c}$, and precipitation particles $q_{r}$ ) in a single cloud field simulation. The first set is coupled to the dynamics $(u, v$, and $w$ wind components in the figure) and drives the simulation (set D, as in "driving"). The coupling is represented in the figure by the red lines with arrows at both ends. Thermodynamic variables from the second set are advected by the flow and are exposed to the same physical processes as in the driving set (e.g., surface fluxes, phase changes, precipitation fallout, etc.). However, they do not affect local buoyancy and thus do not impact the simulated flow. Hence, the second set "piggybacks" the flow and it is referred to as the P set (as in "piggybacking"). This is marked in the figure by the red lines with arrows pointing from the dynamics to the thermodynamics only. An important element of the piggybacking approach is swapping thermodynamic sets in the second simulation so the $\mathrm{D}$ set becomes the $\mathrm{P}$ set, and vice versa. This is the key difference between the right and left panels in Fig. A1. Although flow evolutions are typically different between the left and right panels, the focus is on comparing the driver-piggybacker differences between the two simulations as shown in past applications of this approach.

In the initial applications of the piggybacking approach, the focus was on the cloud microphysics, for instance, comparing cloud field simulations applying different microphysics schemes or different scheme parameters (Grabowski 2014, 2015; Grabowski and 

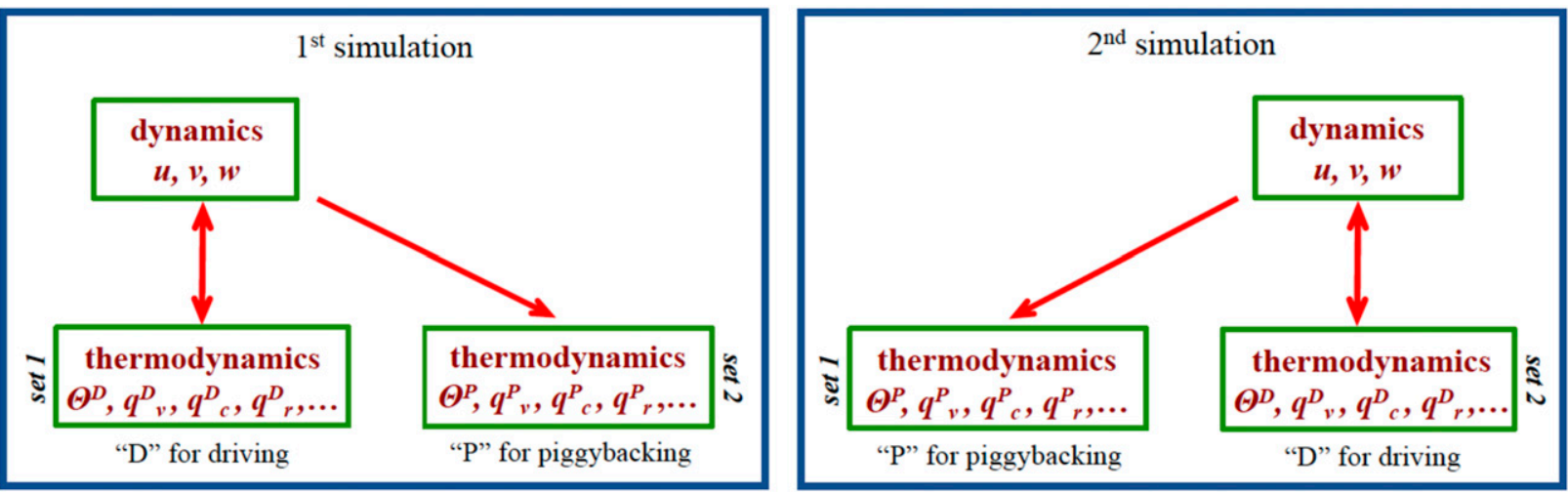

FIG. A1. Illustration of the piggybacking methodology. See text for explanation.

Jarecka 2015; Grabowski and Morrison 2016, 2017). Such simulations applied the same initial sounding for both the driver and the piggybacker thermodynamic sets. The motivation for applying piggybacking in those simulations came from the observation that even a small change in the model physics (e.g., of a microphysics scheme parameter) led after some time to a different flow evolution. This was illustrated in the application of the method to shallow precipitating convection in Grabowski (2014, see Figs. 2 and 3 there). For the modeling setup applied in the current study [the case of Grabowski et al. (2006)], this is illustrated by Fig. 2 in Grabowski and Morrison (2016) that shows that flow realizations are similar between drivers for the shallow convection phase (i.e., after $2 \mathrm{~h}$ ), but they differ significantly for the deep convection phase at hour 6 . As a result, separating the scheme or parameter impact from the natural variability of the simulated system (i.e., different flow realizations when a scheme or parameter is changed) is difficult without piggybacking. More recently, piggybacking was applied in simulations where one of the thermodynamic sets applied homogenization of the cloud environment to explore whether environmental heterogeneities, such as remnants of previous clouds, affect subsequent cloud developments; Kurowski et al. (2019). Grabowski (2018) applied piggybacking in series of simulations where the two sets of thermodynamic variables differed in the initial sounding (e.g., slightly different temperature or moisture profiles) or different forcing (modified Bowen ratio of the surface flux or prescribed large-scale moisture and temperature tendencies).

Simulations discussed in this paper contrast daytime convection development applying the current climate morning sounding and soundings modified because of the projected climate change as explained in the main text.

\section{REFERENCES}

Alexander, L. V., and Coauthors, 2006: Global observed changes in daily climate extremes of temperature and precipitation. J. Geophys. Res., 111, D05109, https://doi.org/10.1029/ 2005JD006290.

Allen, M. R., and W. J. Ingram, 2002: Constraints on future changes in climate and the hydrologic cycle. Nature, 419, 228-232, https://doi.org/10.1038/nature01092.

Bador, M., M. G. Donat, O. Geoffroy, and L. V. Alexander, 2018: Assessing the robustness of future extreme precipitation intensification in the CMIP5 ensemble. J. Climate, 31, 65056525, https://doi.org/10.1175/JCLI-D-17-0683.1.

Ban, N., J. Schmidli, and C. Schär, 2014: Evaluation of the convection-resolving regional climate modeling approach in decade-long simulations. J. Geophys. Res., 119, 7889-7907, https://doi.org/10.1002/2014JD021478.

,-- , and -2015 : Heavy precipitation in a changing climate: Does short-term summer precipitation increase faster? Geophys. Res. Lett., 42, 1165-1172, https://doi.org/10.1002/ 2014GL062588.

_ _ J. Rajczak, J. Schmidli, and C. Schär, 2018: Analysis of Alpine precipitation extremes using generalized extreme value theory in convection-resolving climate simulations. Climate Dyn., https://doi.org/10.1007/S00382-018-4339-4.

Bretherton, C. S., M. E. Peters, and L. E. Back, 2004: Relationships between water vapor path and precipitation over the tropical oceans. J. Climate, 17, 1517-1528, https://doi.org/10.1175/15200442(2004)017<1517:RBWVPA $>2.0 . \mathrm{CO} ; 2$.

Bryan, G. H., and H. Morrison, 2012: Sensitivity of a simulated squall line to horizontal resolution and parameterization of microphysics. Mon. Wea. Rev., 140, 202-225, https://doi.org/ 10.1175/MWR-D-11-00046.1.

Chan, S. C., E. J. Kendon, H. J. Fowler, S. Blenkinsop, N. M. Roberts, and C. A. Ferro, 2014: The value of high-resolution Met Office regional climate models in the simulation of multihourly precipitation extremes. J. Climate, 27, 6155-6174, https://doi.org/10.1175/JCLI-D-13-00723.1.

Del Genio, A. D., M. S. Yao, and J. Jonas, 2007: Will moist convection be stronger in a warmer climate? Geophys. Res. Lett., 34, L16703, https://doi.org/10.1029/2007GL030525.

Derbyshire, S. H., I. Beau, P. Bechtold, J.-Y. Grandpeix, J.-M. Piriou, J.-L. Redelsperger, and P. M. M. Soares, 2004: Sensitivity of moist convection to environmental humidity. Quart. 
J. Roy. Meteor. Soc., 130, 3055-3079, https://doi.org/10.1256/ qj.03.130.

Giorgi, F., E. S. Im, E. Coppola, N. S. Diffenbaugh, X. J. Gao, L. Mariotti, and Y. Shi, 2011: Higher hydroclimatic intensity with global warming. J. Climate, 24, 5309-5324, https://doi.org/ 10.1175/2011JCLI3979.1.

Grabowski, W. W., 2014: Extracting microphysical impacts in large-eddy simulations of shallow convection. J. Atmos. Sci., 71, 4493-4499, https://doi.org/10.1175/JAS-D-14-0231.1.

- 2015: Untangling microphysical impacts on deep convection applying a novel modeling methodology. J. Atmos. Sci., 72, 2446-2464, https://doi.org/10.1175/JAS-D-14-0307.1.

_ 2018: Can the impact of aerosols on deep convection be isolated from meteorological effects in atmospheric observations? J. Atmos. Sci., 75, 3347-3363, https://doi.org/10.1175/ JAS-D-18-0105.1.

— , and D. Jarecka, 2015: Modeling condensation in shallow nonprecipitating convection. J. Atmos. Sci., 72, 4661-4679, https://doi.org/10.1175/JAS-D-15-0091.1.

_- and H. Morrison, 2016: Untangling microphysical impacts on deep convection applying a novel modeling methodology. Part II: Double-moment microphysics. J. Atmos. Sci., 73, 37493770, https://doi.org/10.1175/JAS-D-15-0367.1.

$\longrightarrow$, and 2017: Modeling condensation in deep convection. J. Atmos. Sci., 74, 2247-2267, https://doi.org/10.1175/JASD-16-0255.1.

— , and Coauthors, 2006: Daytime convective development over land: A model intercomparison based on LBA observations. Quart. J. Roy. Meteor. Soc., 132, 317-344, https://doi.org/ 10.1256/qj.04.147.

_- J. Slawinska, H. Pawlowska, and A. A. Wyszogrodzki, 2011: Macroscopic impacts of cloud and precipitation processes in shallow convection. Acta Geophys., 59, 1184-1204, https:// doi.org/10.2478/s11600-011-0038-9.

Guerreiro, S. B., H. J. Fowler, R. Barbero, S. Westra, G. Lenderink, S. Blenkinsop, E. Lewis, and X. F. Li, 2018: Detection of continental-scale intensification of hourly rainfall extremes. Nat. Climate Change, 8, 803-807, https://doi.org/ 10.1038/s41558-018-0245-3.

Guichard, F., and Coauthors, 2004: Modelling the diurnal cycle of deep precipitating convection over land with CRMs and SCMs. Quart. J. Roy. Meteor. Soc., 130, 3139-3172, https:// doi.org/10.1256/qj.03.145.

Haerter, J. O., and P. Berg, 2009: Unexpected rise in extreme precipitation caused by a shift in rain type? Nat. Geosci., 2 , 372-373, https://doi.org/10.1038/ngeo523.

Held, I. M., and B. J. Soden, 2006: Robust responses of the hydrological cycle to global warming. J. Climate, 19, 5686-5699, https://doi.org/10.1175/JCLI3990.1.

Hoogewind, K. A., M. E. Baldwin, and R. J. Trapp, 2017: The impact of climate change on hazardous convective weather in the United States: Insight from high-resolution dynamical downscaling. J. Climate, 30, $10081-10100$, https://doi.org/ 10.1175/JCLI-D-16-0885.1.

Huntington, T. G., 2006: Evidence for intensification of the global water cycle: Review and synthesis. J. Hydrol., 319, 83-95, https://doi.org/10.1016/j.jhydrol.2005.07.003.

IPCC, 2013: Climate Change 2013: The Physical Science Basis. T. F. Stocker et al., Eds., Cambridge University Press, 1535 pp, https://doi.org/10.1017/CBO9781107415324.

Jones, T. R., and D. A. Randall, 2011: Quantifying the limits of convective parameterizations. J. Geophys. Res., 116, D08210, https://doi.org/10.1029/2010JD014913.
Kawase, H., T. Yoshikane, M. Hara, F. Kimura, T. Yasunari, B. Ailikun, H. Ueda, and T. Inoue, 2009: Intermodel variability of future changes in the Baiu rainband estimated by the pseudo global warming downscaling method. J. Geophys. Res., 114, D24110, https://doi.org/10.1029/2009JD011803.

Kendon, E. J., N. M. Roberts, H. J. Fowler, M. J. Roberts, S. C. Chan, and C. A. Senior, 2014: Heavier summer downpours with climate change revealed by weather forecast resolution model. Nat. Climate Change, 4, 570-576, https://doi.org/ 10.1038/nclimate2258.

Khairoutdinov, M., and D. Randall, 2006: High-resolution simulation of shallow-to-deep convection transition over land. J. Atmos. Sci., 63, 3421-3436, https://doi.org/10.1175/JAS3810.1.

Knutson, T. R., and Coauthors, 2010: Tropical cyclones and climate change. Nat. Geosci., 3, 157-163, https://doi.org/10.1038/ ngeo779.

Kurowski, M. J., K. Suselj, W. W. Grabowski, and J. Teixeira, 2018: Shallow-to-deep transition of continental moist convection: Cold pools, surface fluxes, and mesoscale organization. J. Atmos. Sci., 75, 4071-4090, https://doi.org/10.1175/JAS-D-18-0031.1.

,-- and -2019 : Is shallow convection sensitive to environmental heterogeneities? Geophys. Res. Lett., 46, 17851793, https://doi.org/10.1029/2018GL080847.

Laîné, A., H. Nakamura, K. Nishii, and T. Miyasaka, 2014: A diagnostic study of future evaporation changes projected in CMIP5 climate models. Climate Dyn., 42, 2745-2761, https:// doi.org/10.1007/s00382-014-2087-7.

Lebo, Z. J., and H. Morrison, 2015: Effects of horizontal and vertical grid spacing on mixing in simulated squall lines and implications for convective strength and structure. Mon. Wea. Rev., 143, 4355-4375, https://doi.org/10.1175/MWR-D-15-0154.1.

Lenderink, G., and E. van Meijgaard, 2008: Increase in hourly precipitation extremes beyond expectations from temperature changes. Nat. Geosci., 1, 511-514, https://doi.org/10.1038/ngeo262.

Min, S. K., X. Zhang, F. W. Zwiers, and G. C. Hegerl, 2011: Human contribution to more-intense precipitation extremes. Nature, 470, 378-381, https://doi.org/10.1038/nature09763.

Molinari, J., and M. Dudek, 1992: Parameterization of convective precipitation in mesoscale numerical models: A critical review. Mon. Wea. Rev., 120, 326-344, https://doi.org/10.1175/ 1520-0493(1992)120<0326:POCPIM > 2.0.CO;2.

Mooney, P. A., C. Broderick, C. L. Bruyère, F. J. Mulligan, and A. F. Prein, 2017: Clustering of observed diurnal cycles of precipitation over the United States for evaluation of a WRF multiphysics regional climate ensemble. J. Climate, 30, 92679286, https://doi.org/10.1175/JCLI-D-16-0851.1.

Morrison, H., and W. W. Grabowski, 2007: Comparison of bulk and bin warm-rain microphysics models using a kinematic framework. J. Atmos. Sci., 64, 2839-2861, https://doi.org/10.1175/JAS3980.

_, and _ 2008a: Modeling supersaturation and subgrid-scale mixing with two-moment bulk warm microphysics. J. Atmos. Sci., 65, 792-812, https://doi.org/10.1175/2007JAS2374.1.

- and - 2008b: A novel approach for representing ice microphysics in models: Description and tests using a kinematic framework. J. Atmos. Sci., 65, 1528-1548, https://doi.org/ 10.1175/2007JAS2491.1.

Muller, C. J. and P. A. O'Gorman, 2011: An energetic perspective on the regional response of precipitation to climate change. Nat. Climate Change, 1, 266-271, https://doi.org/10.1038/nclimate1169. , L. E. Back, P. A. O'Gorman, and K. A. Emanuel, 2009: A model for the relationship between tropical precipitation and column water vapor. Geophys. Res. Lett., 36, L16804, https:// doi.org/10.1029/2009GL039667. 
_ P. A. O'Gorman, and L. E. Back, 2011: Intensification of precipitation extremes with warming in a cloud-resolving model. J. Climate, 24, 2784-2800, https://doi.org/10.1175/2011JCLI3876.1.

Neelin, J. D., O. Peters, and K. Hales, 2009: The transition to strong convection. J. Atmos. Sci., 66, 2367-2384, https://doi.org/ 10.1175/2009JAS2962.1.

O'Gorman, P. A., and T. Schneider, 2009: The physical basis for increases in precipitation extremes in simulations of 21stcentury climate change. Proc. Natl. Acad. Sci. USA, 106, 14 773-14 777, https://doi.org/10.1073/pnas.0907610106.

, and C. J. Muller, 2010: How closely do changes in surface and column water vapor follow Clausius-Clapeyron scaling in climate change simulations? Environ. Res. Lett., 5, 025207 , https://doi.org/10.1088/1748-9326/5/2/025207.

Prein, A. F., A. Gobiet, M. Suklitsch, H. Truhetz, N. K. Awan, K. Keuler, and G. Georgievski, 2013: Added value of convection permitting seasonal simulations. Climate Dyn., 41, 2655-2677, https://doi.org/10.1007/s00382-013-1744-6.

—, and Coauthors, 2015: A review on regional convectionpermitting climate modeling: Demonstrations, prospects, and challenges. Rev. Geophys., 53, 323-361, https://doi.org/ 10.1002/2014RG000475.

- C. Liu, K. Ikeda, S. B. Trier, R. M. Rasmussen, G. J. Holland, and M. P. Clark, 2017a: Increased rainfall volume from future convective storms in the US. Nat. Climate Change, 7, 880-884, https://doi.org/10.1038/s41558-017-0007-7.

, R. M. Rasmussen, K. Ikeda, C. Liu, M. P. Clark, and G. J. Holland, 2017b: The future intensification of hourly precipitation extremes. Nat. Climate Change, 7, 48-52, https:// doi.org/10.1038/nclimate3168.

Rasmussen, K. L., A. F. Prein, R. M. Rasmussen, K. Ikeda, and C. Liu, 2017: Changes in the convective population and thermodynamic environments in convection-permitting regional climate simulations over the United States. Climate Dyn., https://doi.org/10.1007/S00382-017-4000-7.

Rasmussen, R., and Coauthors, 2011: High-resolution coupled climate runoff simulations of seasonal snowfall over Colorado: A process study of current and warmer climate. J. Climate, 24, 3015-3048, https://doi.org/10.1175/2010JCLI3985.1.

Romps, D. M., 2011: Response of tropical precipitation to global warming. J. Atmos. Sci., 68, 123-138, https://doi.org/10.1175/2010JAS3542.1.

- 2016: Clausius-Clapeyron scaling of CAPE from analytical solutions to RCE. J. Atmos. Sci., 73, 3719-3737, https://doi.org/ 10.1175/JAS-D-15-0327.1.

Schär, C., C. Frei, D. Lüthi, and H. C. Davies, 1996: Surrogate climatechange scenarios for regional climate models. Geophys. Res. Lett., 23, 669-672, https://doi.org/10.1029/96GL00265.
_ - and Coauthors, 2016: Percentile indices for assessing changes in heavy precipitation events. Climatic Change, 137, 201-216, https://doi.org/10.1007/s10584-016-1669-2.

Sherwood, S. C., S. Bony, and J. L. Dufresne, 2014: Spread in model climate sensitivity traced to atmospheric convective mixing. Nature, 505, 37-42, https://doi.org/10.1038/nature12829.

Takemi, T., O. Hirayama, and C. Liu, 2004: Factors responsible for the vertical development of tropical oceanic cumulus convection. Geophys. Res. Lett., 31, L11109, https://doi.org/ 10.1029/2004GL020225.

Thackeray, C. W., A. M. DeAngelis, A. Hall, D. L. Swain, and X. Qu, 2018: On the connection between global hydrologic sensitivity and regional wet extremes. Geophys. Res. Lett., $\mathbf{4 5}$, 11343-11351, https://doi.org/10.1029/2018GL079698.

Thomas, L., N. Malap, W. W. Grabowski, K. Dani, and T. V. Prabha, 2018: Convective environment in pre-monsoon and monsoon conditions over the Indian subcontinent: The impact of surface forcing. Atmos. Chem. Phys., 18, 7473-7488, https:// doi.org/10.5194/acp-18-7473-2018.

Trenberth, K. E., A. Dai, R. M. Rasmussen, and D. B. Parsons, 2003 The changing character of precipitation. Bull. Amer. Meteor. Soc., 84, 1205-1218, https://doi.org/10.1175/BAMS-84-9-1205.

- , Y. Zhang, and M. Gehne, 2017: Intermittency in precipitation: Duration, frequency, intensity, and amounts using hourly data. J. Hydrometeor., 18, 1393-1412, https://doi.org/ 10.1175/JHM-D-16-0263.1.

van Vuuren, D. P., and Coauthors, 2011: The representative concentration pathways: an overview. Climatic Change, 109, 5-31, https://doi.org/10.1007/s10584-011-0148-z.

Westra, S., L. V. Alexander, and F. W. Zwiers, 2013: Global increasing trends in annual maximum daily precipitation. J. Climate, 26, 3904-3918, https://doi.org/10.1175/JCLI-D-12-00502.1.

— , and Coauthors, 2014: Future changes to the intensity and frequency of short-duration extreme rainfall. Rev. Geophys., 52, 522-555, https://doi.org/10.1002/2014RG000464.

Wu, C. M., B. Stevens, and A. Arakawa, 2009: What controls the transition from shallow to deep convection? J. Atmos. Sci., 66, 1793-1806, https://doi.org/10.1175/2008JAS2945.1.

Zhang, L., K. B. Karnauskas, J. P. Donnelly, and K. Emanuel, 2017 Response of the North Pacific tropical cyclone climatology to global warming: Application of dynamical downscaling to CMIP5 models. J. Climate, 30, 1233-1243, https://doi.org/ 10.1175/JCLI-D-16-0496.1.

Zhang, X., F. W. Zwiers, G. Li, H. Wan, and A. J. Cannon, 2017: Complexity in estimating past and future extreme shortduration rainfall. Nat. Geosci., 10, 255-259, https://doi.org/ 10.1038/ngeo2911. 